\title{
Experimental Study on Well Placement Optimization for Steam- Assisted Gravity Drainage to Enhance Recovery of Thin Layer Oil Sand Reservoirs
}

\author{
Lei Tao, ${ }^{1}$ Xiao Yuan, ${ }^{1}$ Hao Cheng, ${ }^{1}$ Bingchao Li, ${ }^{1}$ Sen Huang, ${ }^{1}$ and Na Zhang ${ }^{2}$ \\ ${ }^{1}$ College of Petroleum Engineering, Changzhou University, Changzhou 213164, China \\ ${ }^{2}$ College of Petrochemical Engineering, Changzhou University, Changzhou 213164, China
}

Correspondence should be addressed to Na Zhang; zhangna3021@126.com

Received 10 March 2021; Revised 11 June 2021; Accepted 19 June 2021; Published 22 July 2021

Academic Editor: Weijun Shen

Copyright ( 2021 Lei Tao et al. This is an open access article distributed under the Creative Commons Attribution License, which permits unrestricted use, distribution, and reproduction in any medium, provided the original work is properly cited.

\begin{abstract}
SAGD (steam-assisted gravity drainage) technique is one of the most efficient thermal recovery technologies for exploiting Mackay River thin layer oil sand reservoirs. However, when making use of the traditional SAGD technique (the production and injection well are located on the same axis with the horizontal well spacing of $0 \mathrm{~m}$ ), the steam chamber development is usually insufficient because of the high longitudinal sweep rate of steam, which seriously influences the SAGD performance for developing thin layer oil sand reservoirs especially. It is extremely important to find an economical and practicable method to promote the steam chamber development in thin oil sand reservoirs in the process of SAGD production; optimizing well placement is a reliable method. In this paper, an improved well placement method is proposed to enhance production performance of traditional SAGD, which is changing the horizontal well spacing to place the production well below of the side of the injection well (two wells are not located on the same axis). Three groups of $2 \mathrm{D}$ visualization experiments with different horizontal distances between two wells $(0 \mathrm{~cm}, 10 \mathrm{~cm}$, and $20 \mathrm{~cm})$ were carried out, respectively, to observe the development and change of the steam chamber development, and to explore the EOR mechanisms. On the 2D experiment basis, optimal horizontal distance was selected to perform 3D physical simulation experiment to study and verity the production mechanism systematically. The results of $2 \mathrm{D}$ visualization experiment showed that the final oil recoveries of experimental groups with $10 \mathrm{~cm}$ and $20 \mathrm{~cm}$ horizontal distances were $7.6 \%$ and $2.3 \%$ higher than those of traditional SGAD (horizontal distance was $0 \mathrm{~cm}$ ), respectively. Combined with 3D experimental results, the change in the horizontal relative position of two wells makes the steam first spread laterally between injecting and producing wells; thus, the lateral development of the steam chamber was promoted, and changes of temperature field also display that the lateral sweep area of steam was increased obviously and the form of steam chamber is changed. Meanwhile, the generation of appropriate horizontal well spacing can combine the effect of steam displacement and gravity drainage better and improve the sweep efficiency of steam. Nevertheless, the overlarge horizontal well spacing will also hinder the steam chamber development because the strength of steam overlap is weakened. Furthermore, the findings of this study help for better understanding that changing the horizontal well spacing can promote the lateral development of steam chamber, which can be used to enhance the oil recovery of thin layer oil sand reservoirs especially.
\end{abstract}

\section{Introduction}

With the rapid development of economy and society, conventional oil and gas resources unable to meet the increase of energy demand; therefore, more and more attention has been paid to heavy oil and oil sands [1-3]. The oil sand resources are widely distributed in the world and have huge reserves, and Canada oil sands account for about $81 \%$ of the total reserves [4]; therefore, oil sand has a particularly important strategic position in the national energy security. However, the viscosity of Mackay River oil sand is extremely high under initial reservoir conditions, which causes the oil almost immobile [5-7]. Technically, the classic method to lower the viscosity of heavy oil is thermal recovery, and the steam is usually served as the heat medium [8]. Conventional thermal recoveries, such as steam huff and puff, steam 
flooding, and the combustion of oil in situ $[9,10]$, have been widely used in heavy oil and oil sand exploitation. Nevertheless, these conventional methods have some defect including limited heating radius, steam channeling, and a lot of steam consumption. Recently, as one of the most effective thermal recovery methods, steam-assisted gravity drainage (SAGD) technique, which was first proposed by Butler et al., in the 1980s, has been a widely applied technique for heavy oil and oil sand reservoirs, especially in thick formations with extra heavy oil [11-16].

In the SAGD production process, dual horizontal wells are drilled near the bottom of oil reservoirs, as shown in Figure 1, injecting high-temperature steam from the upper horizontal well to transfer and exchange heat with the reservoir, resulting in that the viscosity of heavy oil was drastically reduced, so the heavy oil can flow into the bottom well by gravity [17-21]; then, subsequent injected steam fills the spaces occupied by the heavy oil before, forming a uniform and stable steam chamber with an inverted triangular cross section [22-25]. The development process of steam chamber usually can be divided into three stages, including the stage of rising, transverse expansion, and descent [26].

From past to present, a lot of subsequent simulations and experiments have been carried out to investigate and improve SAGD technique. Based on Butler's theoretical research, Chung systematically explained the similarity criteria required for SAGD physical simulation process, which made the results of indoor research more authentic and reliable, providing an effective basis for actual production [27]. Nukhaev et al. presented a new analytical model of the SAGD production regime; the water-oil ratio in producing fluid at the different stages of production was estimated precisely [28]. Siavashi et al. used a numerical simulation to analyze the influence of steam injection temperature, well rates, and different distances between injection-production wells $(9,14,20$, and $27 \mathrm{~m}$ ) on oil recovery in SAGD process; the result showed that the steam temperature and well distance remarkably had an effect on SAGD performance; the oil production increased with well distance widening [29]. Dong et al. developed sensitivity analysis model to comprehensively evaluate the influences of reservoir/fluid parameters and operation parameters on SAGD recovery performance, which confirmed that reservoir thickness, permeability, and pressure have great influence on SAGD production [30]. Zhang et al. used a $2 \mathrm{D}$ numerical model to predict the lateral spreading and confinement stage of steam chamber, and they also found that a higher steam pressure results in a higher oil rate [31]. Munoz established a twodimensional numerical simulation model to study the effect of bottom water on SAGD production for oil reservoirs in Alberta, Canada. The simulation result showed that the bottom water can cause steam heat loss; in addition, placing the producing well at the bottom of the reservoir can enhance recovery to the maximum extent in the absence of bottom water [32]. In addition, interlayer can also have an impact on SAGD production, Dou and $\mathrm{Li}$ carried out a thermal recovery physical simulation experiment to study the influence of interlayer on steam cham- ber, and the result showed that the steam chamber was forced to develop laterally along the interlayer [33]. Meanwhile, in order to enhance SAGD recovery, multiple media-assisted SAGD technologies such as expanding solvent-SAGD, noncondensate gas-assisted SAGD $\left(\mathrm{CO}_{2}, \mathrm{~N}_{2}\right.$, flue gas, and natural gas), and foam-assisted SAGD have been proposed [34-37]. These techniques decreased the steam consumption and steam heat loss; the development of steam chamber is promoted.

In conclusion, while amounts of numerical and physical simulations are conducted to investigate the SAGD technique, which also have made considerable progress, they hardly focus on changing and optimizing well placement to improve the SAGD production performance in the thin layer reservoirs; meanwhile, the difference and the process of steam chamber development after changing well placement is not very clear, so this paper will carry out experimental investigation on this to observe the production process and explore production mechanism by using the improved $2 \mathrm{D}$ and $3 \mathrm{D}$ equipment.

The Mackey River oil sands project in Canada is of great significance for China's energy strategy, and China pays more attention to this important program. However, when making use of the traditional SAGD technique to develop Mackay River oil sands, due to the reservoir characteristics of its thin thickness (thickness was 15-20 m), the steam chamber develops mainly vertically and the steam tends to reach the top at a faster rate, causing that the lateral sweep area of steam is limited and the steam chamber development is not sufficient, with the shape is narrow and long; as shown in Figure 1, the production performance of SAGD technique does not take full advantage. Therefore, this work proposed an improved well placement method that changes the horizontal position of the two wells from the perspective of steam chamber development and production characteristics, as shown in Figures 2 and 3.

In this work, firstly, utilizing the $2 \mathrm{D}$ visualization device, three groups of experiments with different horizontal well spacing between the injection and production wells $(0 \mathrm{~cm}$, $10 \mathrm{~cm}$, and $20 \mathrm{~cm}$ ) were designed to observe the steam chamber development; the change of temperature field distribution with different horizontal well spacing was studied intuitively by temperature monitoring. In addition, several production parameters such as production rate, injectionproduction pressure difference, water cut, cumulative oilsteam ratio, and cumulative oil production changing with time were compared and analyzed. Then, the horizontal well spacing with the best production effect in the $2 \mathrm{D}$ experiment was selected to carry out the $3 \mathrm{D}$ physical simulation experiment; the production performance and mechanism were studied and verified systematically.

\section{Experimental Materials and Methods}

2.1. Similarity Parameter. Due to the limited conditions of laboratory, it is difficult to simulate all the actual onsite production parameters when carrying out the SAGD experiment. Therefore, in order to reflect and conform to the actual situation onsite and to raise the accuracy of the 


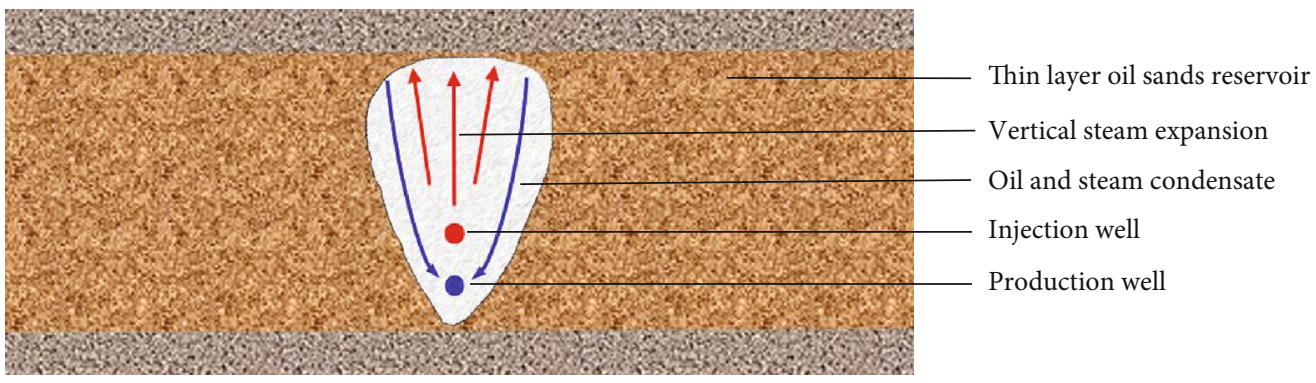

FIgURE 1: The SAGD concept of traditional well placement.

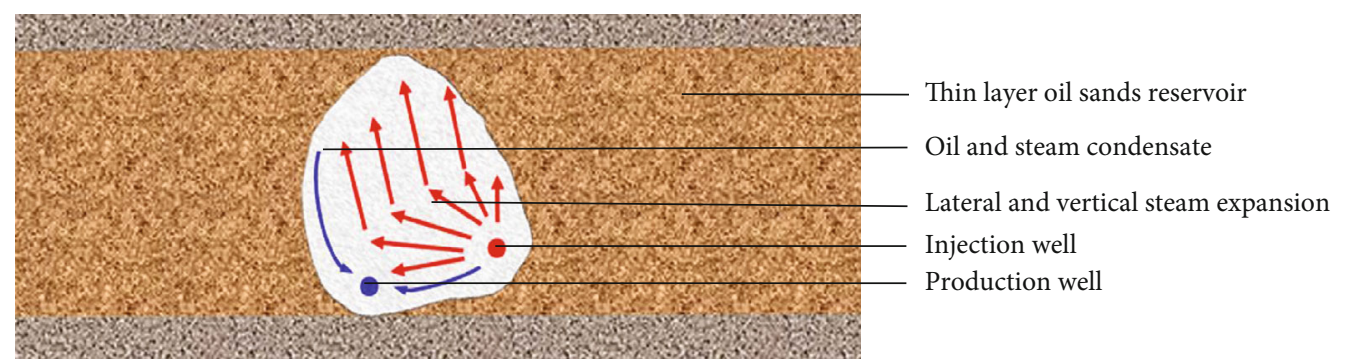

FIGURE 2: The SAGD concept of changing horizontal position between two wells.
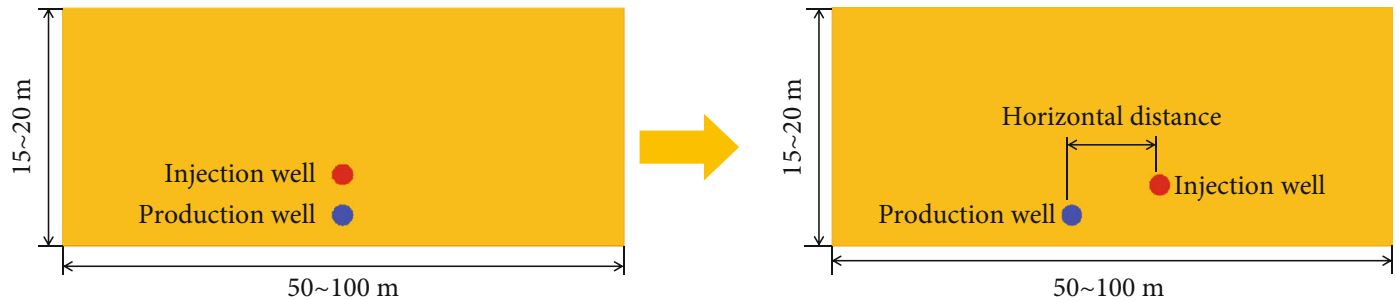

Figure 3: Schematic map for the change of horizontal well pairs placement.

experimental simulation, certain similarity criteria are applied to the design of the experimental apparatus and parameters according to the dominating production factors [38-42].

2.1.1. Similarity Parameter in 2D Experiment. Equation (1) represents the ratio of steam injection volume to movable oil volume, and steam injection intensity can be determined.

$$
\pi_{1}=\frac{i_{s} t}{\varnothing \Delta S \rho_{o} L^{3}},
$$

where $i_{s}$ is the steam injection intensity, $\mathrm{t} / \mathrm{d} ; \Delta S$ refers to the oil saturation; $t$ is the production time, $s ; \varphi$ is the porosity; $\rho_{o}$ is the density of crude oil, $\mathrm{kg} / \mathrm{m}^{3} ; L$ is the length of horizontal well, $\mathrm{m}$.

During the SAGD process, gravity provides the main driving force. Therefore, the ratio of gravity and viscosity force is an important index, as is showed in Equation (2).

$$
\pi_{2}=\frac{K \rho_{o} g t}{\varnothing \Delta s \mu_{o} L}
$$

where $K$ is the permeability, $10^{-3} \mu \mathrm{m}^{2} ; \rho_{o}$ is the oil density, $\mathrm{kg} / \mathrm{m}^{3} ; \varnothing$ is the porosity; $\Delta S$ is the mobile oil saturation; and $\mu_{0}$ is the oil viscosity, $\mathrm{mPa} \cdot \mathrm{s}$.

Combining $\pi_{1}, \pi_{2}$ and the similarity criterion proposed by Butler, the following criterion number can be acquired; as is shown in Equation (3), $t_{D}$ is a measure of the degree of exploitation.

$$
t_{D}=\frac{t}{h} \sqrt{\frac{K g \alpha \rho_{o}}{\varnothing \Delta S_{o} n v_{s} h \mu_{o}}},
$$

where $K$ is the permeability, $10^{-3} \mu \mathrm{m}^{2} ; g$ is the acceleration of gravity, $\mathrm{m} / \mathrm{s}^{2} ; \alpha$ is the thermal diffusivity, $\mathrm{m}^{2} / \mathrm{s} ; \Delta S_{o}$ is the oil saturation; $n$ is the viscosity temperature characteristic parameter of crude oil; $v_{s}$ is the kinematic viscosity of steam, $\mathrm{m}^{2} / \mathrm{s} ; t$ is the production time, $\mathrm{s} ; \varnothing$ is the porosity; $h$ is the thickness of reservoir, $\mathrm{m} ; n, v_{s}$ is 1 .

These numbers above are used to design the $2 \mathrm{D}$ model and production parameters.

2.1.2. Similarity Parameter in $3 D$ Experiment. The relative ratio of heat transfer rate and heat storage rate is very 
important for SAGD production, which determines the heat diffusion process, as is shown in Equation (4).

$$
F_{o}=\frac{\alpha \cdot t}{h^{2}}
$$

where $\alpha$ is the thermal diffusivity, $\mathrm{m}^{2} / \mathrm{s} ; t$ is the production time, $s ; h$ is the thickness of reservoir, $\mathrm{m}$; and $\alpha=1.85$; that is, the rock/sand thermal diffusivity is equal to 1.85 .

The physical meaning of Equation (5) is the ratio of steam injection volume and movable oil volume, which can determine the steam injection intensity.

$$
\pi_{1}=\frac{i_{s} t}{\varnothing \Delta S \rho_{o} L^{3}},
$$

where $i_{s}$ is the steam injection intensity, t/d; $\Delta S$ is the oil saturation; $t$ is the production time, $s ; \varnothing$ is the porosity; $\rho$ is the oil density, $\mathrm{kg} / \mathrm{m}^{3}$; $L$ is the length of horizontal well, $\mathrm{m}$.

Equation (6) represents the relative ratio of power and loss, which determines the driving effect of bottom hole flow pressure difference between injection and production well.

$$
N_{s}=\frac{L b K \Delta p}{\mu_{o} h Q_{h}},
$$

where $K$ is the permeability, $10^{-3} \mu \mathrm{m}^{2} ; h$ is the thickness of reservoir, $\mathrm{m} ; L$ is the length of the horizontal well section, $\mathrm{m} ; b$ is the horizontal well spacing, $\mathrm{m} ; \Delta p$ is the bottom hole flow pressure difference between the injection and producing well, $\mathrm{MPa} ; Q_{h}$ is the horizontal well production, $\mathrm{m}^{3} / \mathrm{d} ; \mu_{o}$ is the oil viscosity, $\mathrm{mPa} \cdot \mathrm{s}$.

These numbers above are used to design the $3 \mathrm{D}$ model and production parameters.

2.2. Experimental Materials. The degassed and dehydrated oil used in the experiment was from the MacKay River oil sand reservoir in Canada. Figure 4 shows the viscositytemperature curve for the experimental oil. Steam was produced by a steam generator.

\subsection{D Visualization Experiment}

2.3.1. Parameters and Schemes. The thickness of Mackay River oil sand reservoirs is generally about $15 \mathrm{~m}$; therefore, the reservoir height of this experimental model was determined to be $15 \mathrm{~cm}$ according to the similarity criterion. In this part, three experiments were conducted. Experiment no. 1 was traditional SAGD test with $0 \mathrm{~cm}$ horizontal well spacing; the vertical distance of the injection-production well was $5 \mathrm{~cm}$. The horizontal well spacing of experiment no. 2 and experiment no. 3, respectively, were $10 \mathrm{~cm}$ and $20 \mathrm{~cm}$; the vertical distance between two wells was $3 \mathrm{~cm}$. In addition, the producing well was $2 \mathrm{~cm}$ from the bottom of model in three experiments. The detailed experimental parameters are shown in Table 1; the schematic diagram of well placement is shown in Figures 5(a)-5(c).

2.3.2. Apparatus. This experiment primarily investigated the process and change of the steam chamber development on

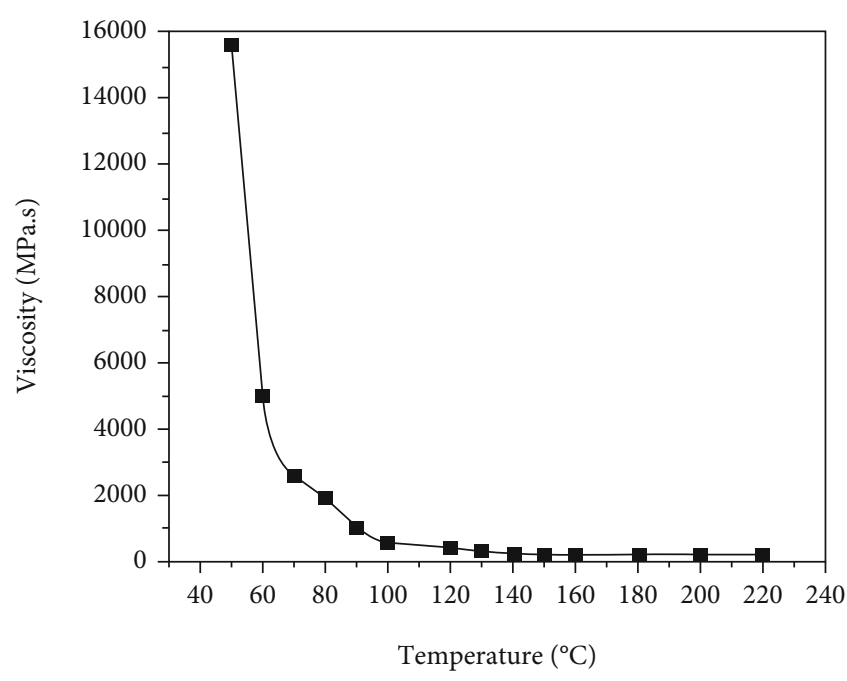

FIgURE 4: Viscosity-temperature relationship of oil used in this experiment.

section with different horizontal distances. The photograph of the experimental setup for $2 \mathrm{D}$ visualization experiment is shown in Figure 6. This part of the experimental equipment was mainly composed of injection system, two-dimensional model, data acquisition system, continuous tracking heating, and insulation system and output system. Figure 7 shows the flow diagram of $2 \mathrm{D}$ visualization experiments in the process of SAGD.

The injection system consisted of ISCO high-precision plunger pump (the 100DX from Teledyne ISCO Company, Teledyne Co., Ltd., Thousand Oaks, CA, USA; flow accuracy $\pm 0.25 \mu \mathrm{l} / \mathrm{min}$ and pressure accuracy $\pm 0.5 \%$ ), steam generator (from Feiyu Technology Co. Ltd., with a temperature range of $450^{\circ} \mathrm{C}$ and pressure range of $25 \mathrm{MPa}$ ), pressure gauge, check valve, cylinder, intermediate container, and gas flow controller (Sla58550, with a flow rate range of $30 \mathrm{ml} / \mathrm{min}$ under standard conditions; Brooks, United States), which can inject oil, water, steam, and flue gas into the model. The data acquisition system was composed of temperature sensor, computer, and digital camera. The inner temperature of the $2 \mathrm{D}$ model was recorded real time by temperature sensor; meanwhile, the real-time changes and characteristics of the steam chamber development were captured by digital camera.

In order to meet the high temperature and pressure working environment of SAGD experiment, and to achieve the visual effect of real-time observation and recording the development changes of steam chamber, in this experiment, an improved 2D physical simulation device was used; it has many advantages and innovations. As shown in Figure 6(a), the model consisted of a high borosilicate glass (HBG) and a stainless-steel frame; its internal size was $500 \mathrm{~mm} \times 500$ $\mathrm{mm} \times 30 \mathrm{~mm}$, which can withstand $3 \mathrm{MPa}$ and $260^{\circ} \mathrm{C}$. A total of 81 high-precision thermocouples with 9 rows and 9 columns were installed inside the $2 \mathrm{D}$ visualization device to monitor real-time temperature, which can more accurately and completely reflect the temperature changes inside the model, as shown in Figures 6(c) and 6(d). Meanwhile, each 
TABle 1: Parameters of 2D experiment.

\begin{tabular}{lcccc}
\hline Parameter & In-site & Experiment no. 1 & Experiment no. 2 & Experiment no. 3 \\
\hline Physical dimension $(\mathrm{m})$ & $50 \times 15$ & $0.5 \times 0.15$ & $0.5 \times 0.15$ & $0.5 \times 0.15$ \\
Vertical well spacing $(\mathrm{m})$ & $3 / 5$ & 0.05 & 0.03 & 0.03 \\
Horizontal well spacing $(\mathrm{m})$ & 0 & 0 & 0.1 & 0.2 \\
Porosity & 0.304 & 0.291 & 21571.1 & 0.29 \\
Permeability $\left(10^{-3} \mu \mathrm{m}^{2}\right)$ & 3522 & 21571.7 & 70.30 & 70.31 \\
Initial oil saturation $(\%)$ & 70.16 & 70.33 & 0.0144 & 0.0144 \\
Steam injection rate $\left(\mathrm{t} \cdot \mathrm{d}^{-1}\right)$ & 1.5 & $0.0144(10 \mathrm{ml} / \mathrm{min})$ & 997 & 997 \\
Oil viscosity $(\mathrm{mPa} \cdot \mathrm{s})$ & 15623 & 997 & 949 & 949 \\
Oil density $\left(\mathrm{kg} \cdot \mathrm{m}^{-3}\right)$ & 1032 & 949 & &
\end{tabular}

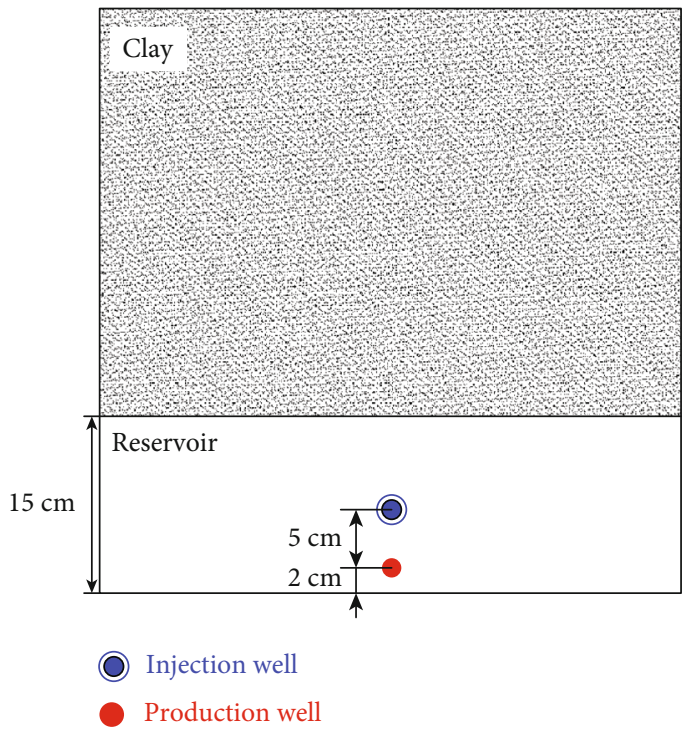

(a)

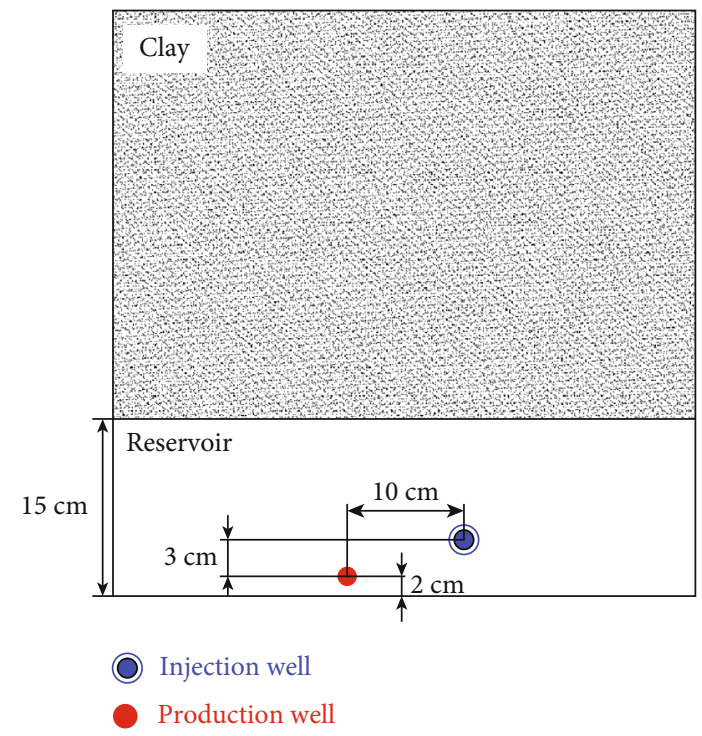

(b)

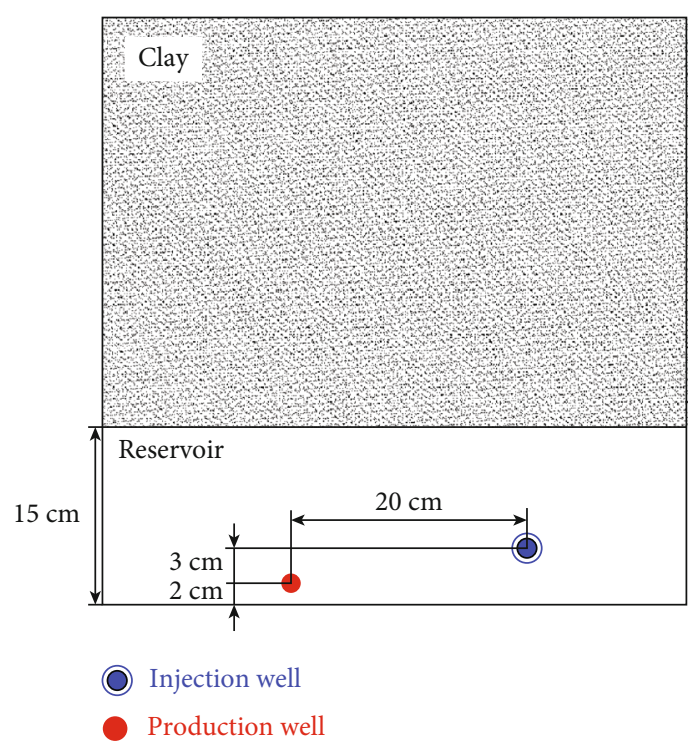

(c)

FIgURE 5: The schematic diagram of well placement. (a) Horizontal distance was $0 \mathrm{~cm}$. (b) Horizontal distance was $10 \mathrm{~cm}$. (c) Horizontal distance was $20 \mathrm{~cm}$. 


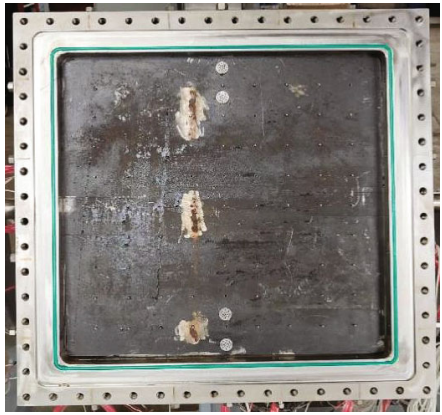

(a)

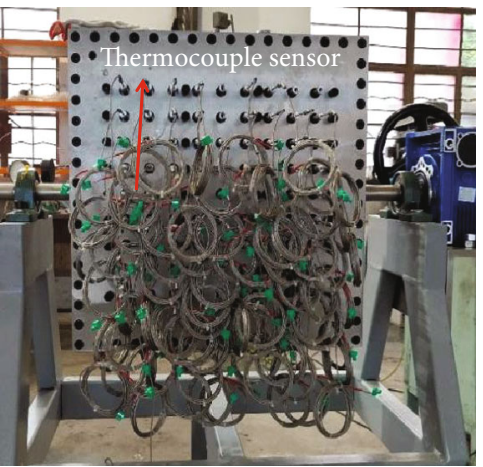

(d)

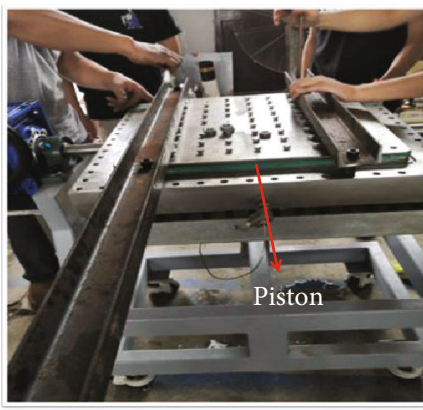

(b)

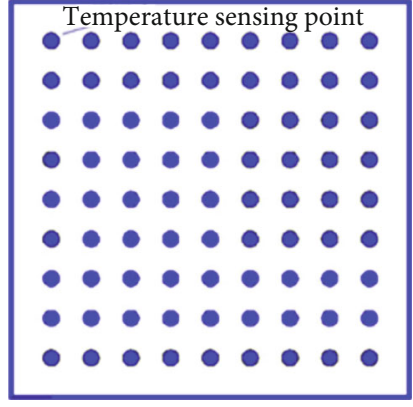

(c)

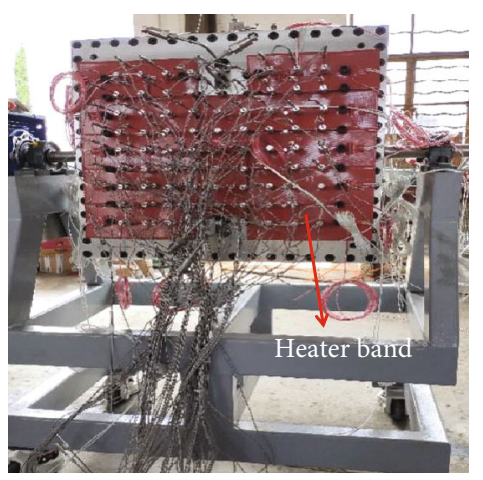

(e)

Figure 6: The 2D visualization device. (a) Internal structure. (b) Piston on the back of model. (c) Distribution of temperature sensing points. (d) Thermocouple sensors. (e) Heater bands.

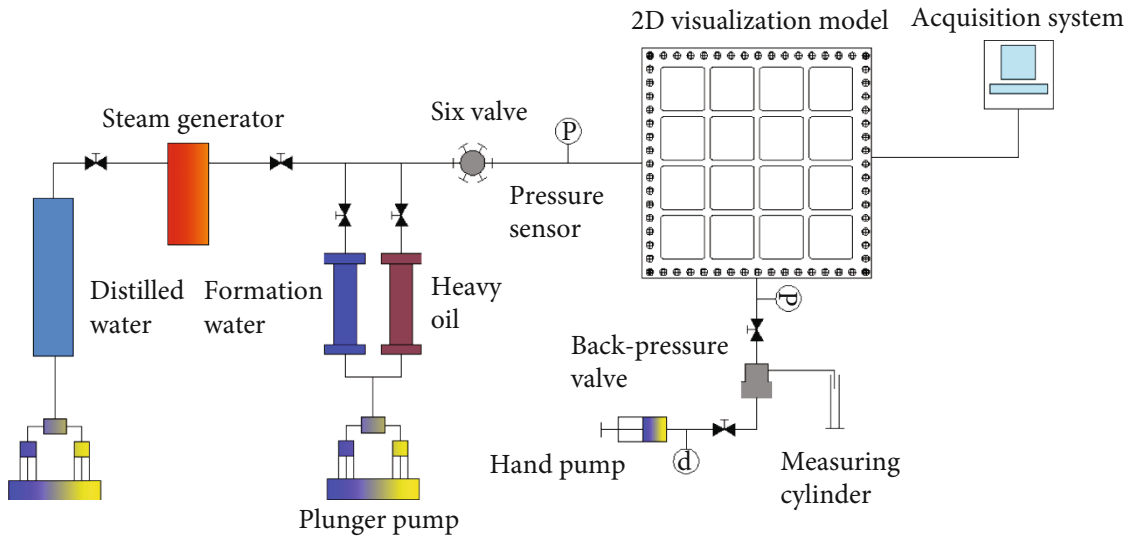

FIgURE 7: Flow diagram of 2D visualization experiments.

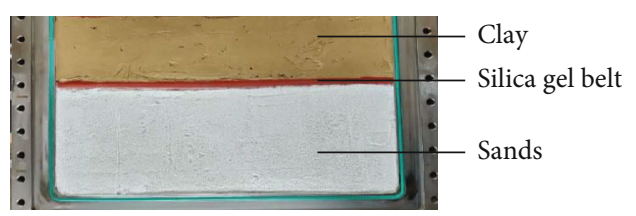

Figure 8: Experimental reservoir thickness.

temperature measuring point was covered by a heating plate; according to the temperature change of different positions, the corresponding heating plates were controlled by the program to continuously heat model, making the temperature inside and outside of model keep the same, which can ensure the continuity of the temperature field, as shown in
TABLE 2: Parameters of 3D experiment.

\begin{tabular}{lcc}
\hline Physical parameter & In-site & Experiment model \\
\hline Physical dimension $(\mathrm{m})$ & $30 \times 30 \times 20$ & $0.3 \times 0.3 \times 0.2$ \\
Horizontal well spacing $(\mathrm{m})$ & 10 & 0.1 \\
Vertical well spacing $(\mathrm{m})$ & 3 & 0.03 \\
Porosity $(\%)$ & 0.304 & 0.46 \\
Permeability $\left(10^{-3} \mathrm{\mu m}^{2}\right)$ & 3522 & 42292.9 \\
Initial oil saturation $(\%)$ & 70.16 & 86.20 \\
Viscosity of oil $(\mathrm{mPa} \cdot \mathrm{s})$ & 15623 & 1005 \\
Density of oil $\left(\mathrm{kg} \cdot \mathrm{m}^{-3}\right)$ & 1032 & 939 \\
Steam injection $\mathrm{rate}\left(\mathrm{t} \cdot \mathrm{d}^{-1}\right)$ & 1.5 & $0.0288(20 \mathrm{ml} / \mathrm{min})$ \\
\hline
\end{tabular}




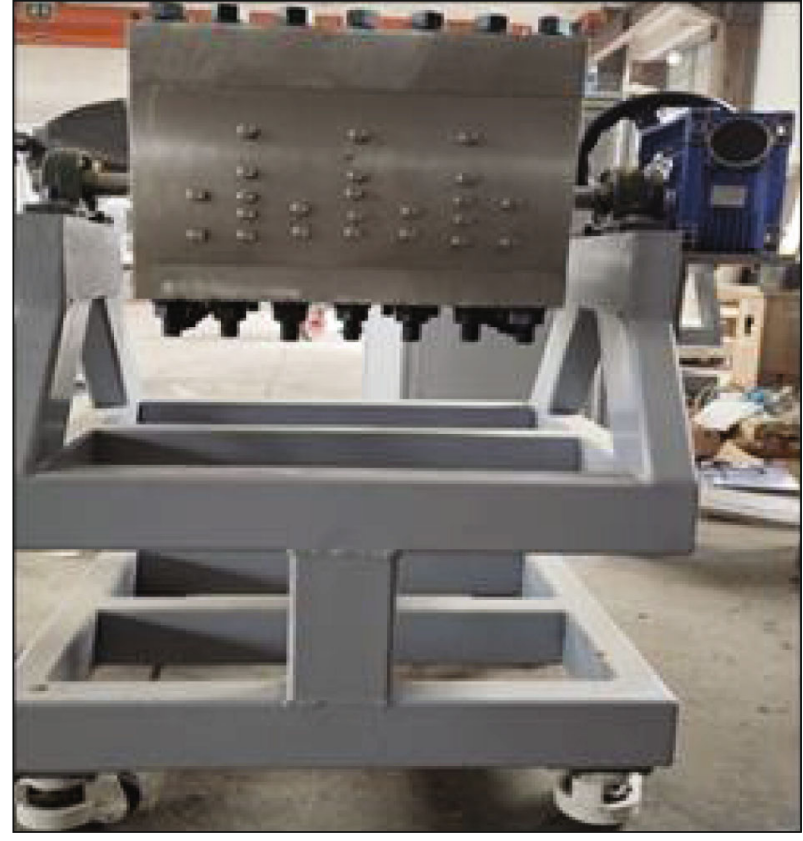

(a)

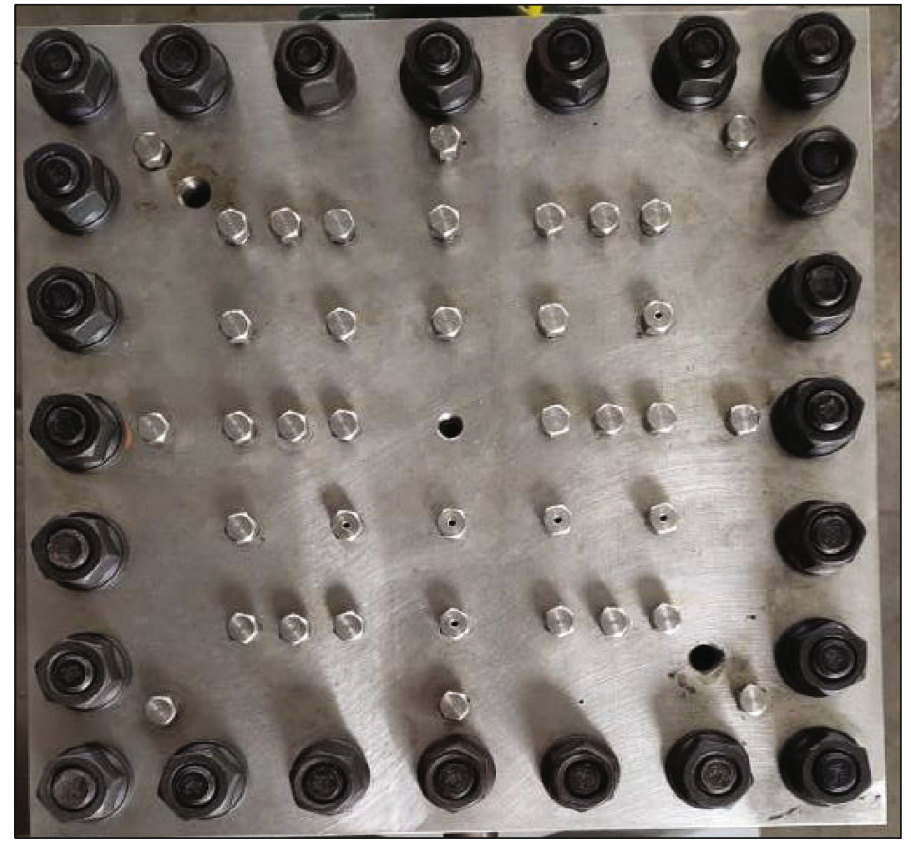

(b)

Figure 9: The 3D physical experiment device. (a) External structure. (b) Temperature measuring points.

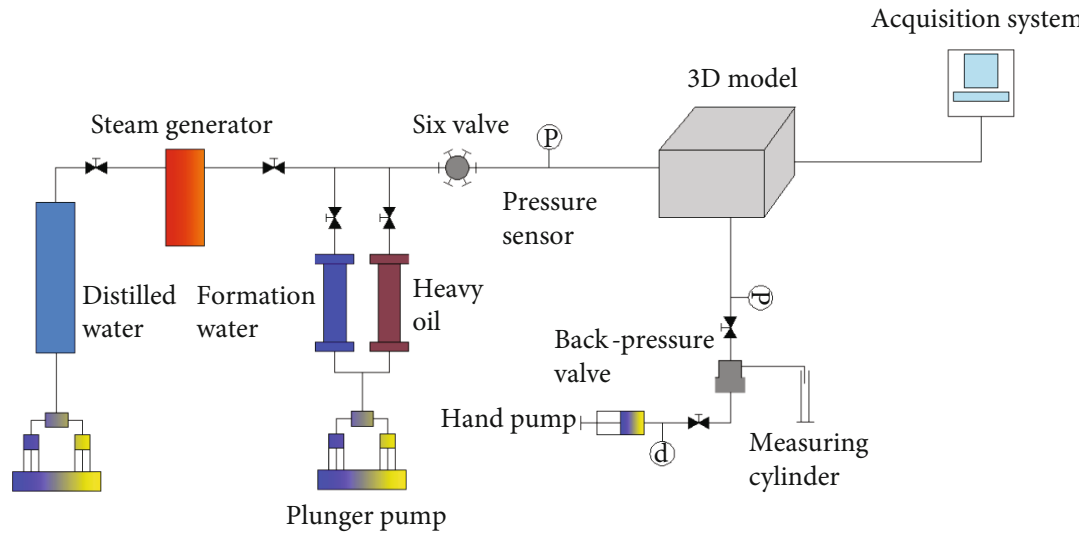

FIGURE 10: Flow diagram of 3D physical experiment.

Figure 6(e). What is more, in order to solve the defect of uneven surface of sand layer caused by manual compaction during sand filling, a piston was designed on the back of the model, which can be pushed by a tightening bolt to compress the sand layer, as shown in Figure 6(b). Finally, the output system was aimed to collect and measure the output oilwater. Computer, temperature sensors, and pressure sensors were constituted a control recording system to collect and process temperature data in each production stage.

2.3.3. Procedures. In order to simulate the onsite reservoir thickness more accurately, a high-temperature resistant silica gel belt was set in the model before filling sands, and the montmorillonite with ultrafine clay particles was filled above it, so that the experimental reservoir thickness can be controlled according to similarity criteria, as shown in Figure 8.
(1) Placed production and injection wells in designated locations according to the experimental plan, and wrapped a sand prevention meshwork of 400 mesh around the simulated well prevent oil sand from blocking wells. Heating rods were placed near the well to preform interwell preheating

(2) Silica sands with 60 mesh were used to pack the $2 \mathrm{D}$ model firstly and then tightened bolts on the back of the model to compress sand layer to proper porosity and permeability. Finally, pressurized to examine the air tightness performance of the visualized model

(3) The model was saturated with distilled water after vacuuming for $8 \mathrm{~h}$. Then, the oil was saturated after heating to $80^{\circ} \mathrm{C}$ through the heating sheet, and the pressure value of the backpressure valve was set as 

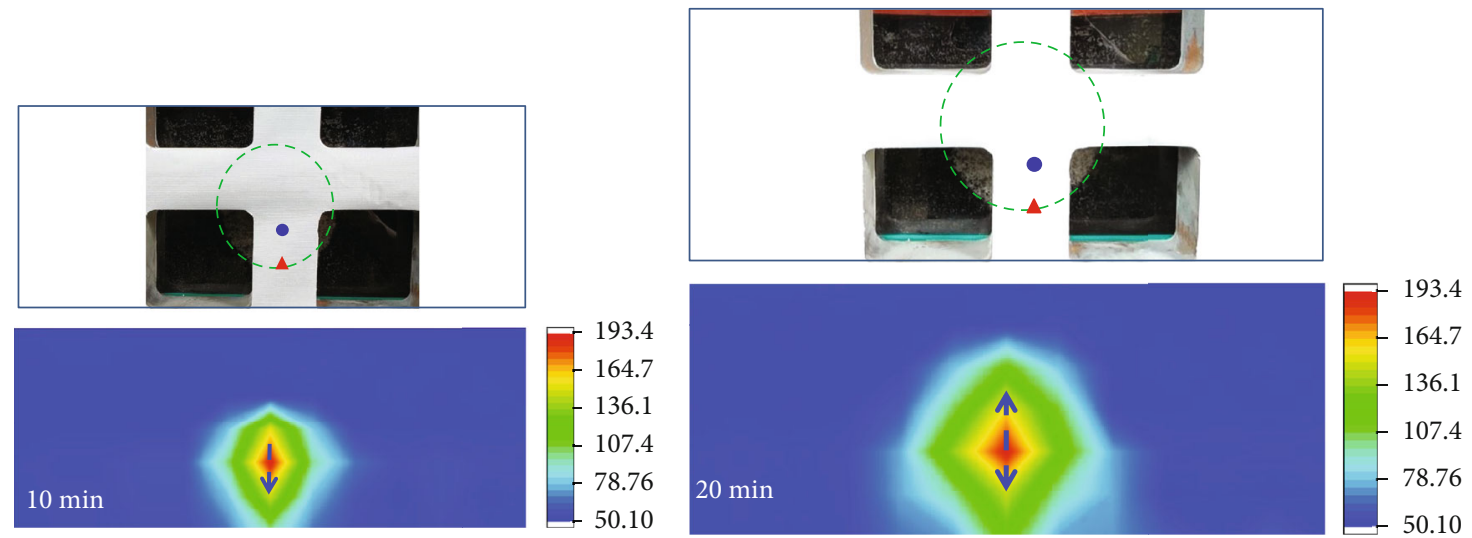

(a)

(b)
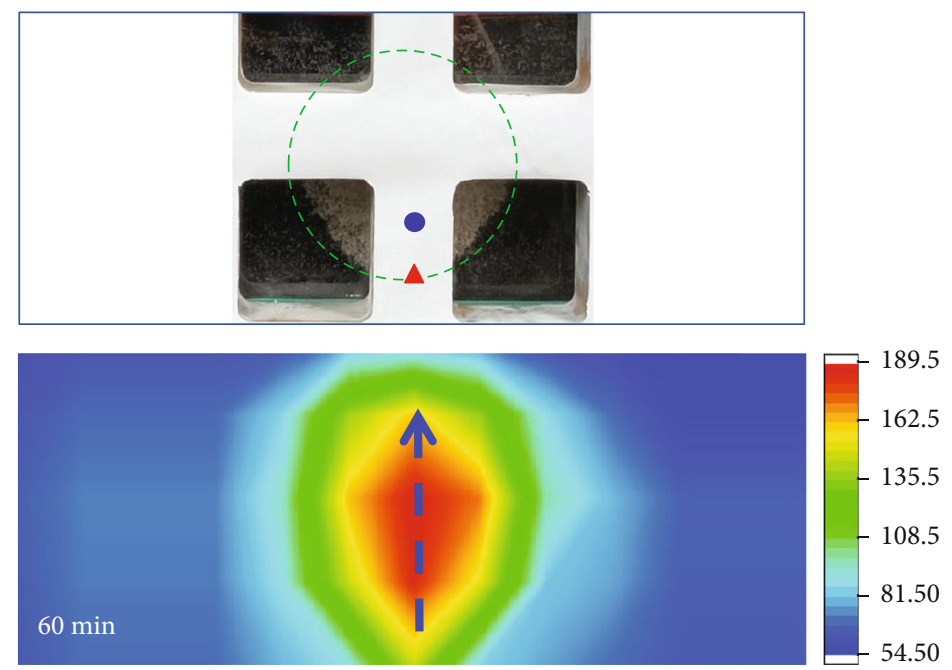

(c)
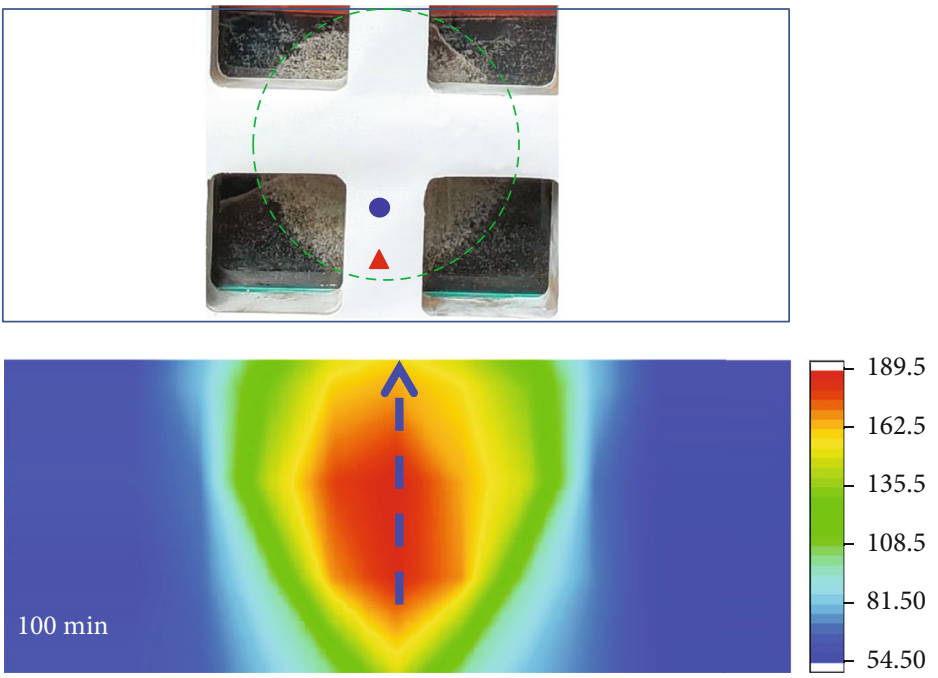

(d)

Figure 11: Continued. 

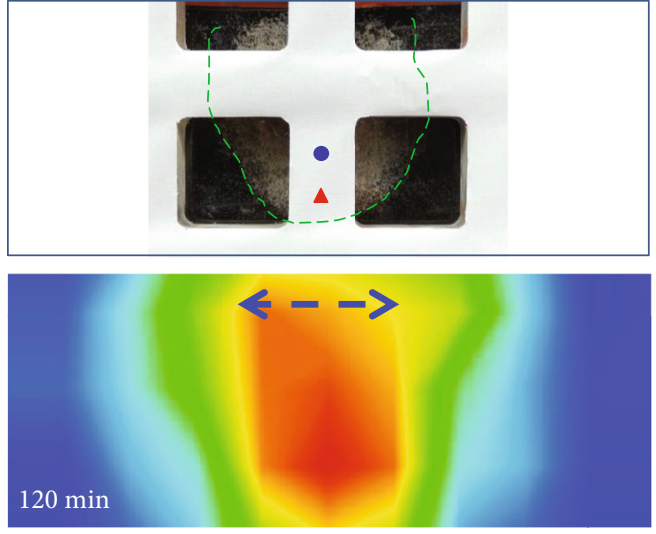

(e)

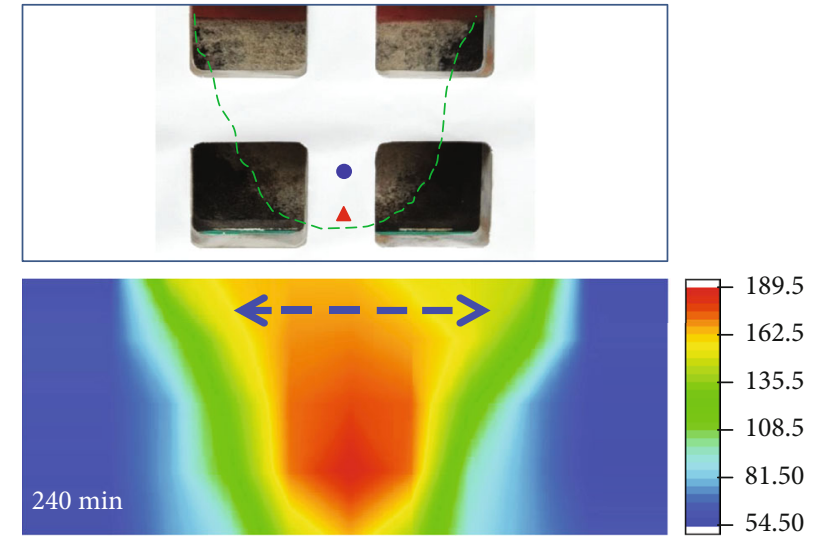

(f)

FIgURE 11: Pictures of steam chamber development and corresponding temperature profiles.

$1 \mathrm{MPa}$. Until there was no water and oil produced, calculated the initial oil saturation, porosity, and permeability

(4) The temperature and pressure of the model were set to $50^{\circ} \mathrm{C}$ and $1 \mathrm{MPa}$. After the model achieved the stable state, steam was injected at the rate of $10 \mathrm{ml} / \mathrm{min}$ (water equivalent). The steam injection temperature was $189^{\circ} \mathrm{C}$. The steam quality was 0.8

(5) In the process of three experiments, the produced oil and water were collected and measured. The 81 temperature transducers recorded the real-time temperature of the model. And the image of the steam chamber development was achieved by digital camera

2.4. 3D Physical Simulation. In order to better study the relevant production mechanism of the misplaced well, a threedimensional physical experiment was conducted on this basis, and the dislocation distance of the injection and production well was also set at $10 \mathrm{~cm}$. The detailed experimental parameters are shown in Table 2.

2.4.1. Apparatus. The 3D model was a cuboid structure, and the maximum operating temperature and pressure of this model were up to $300^{\circ} \mathrm{C}$ and $10 \mathrm{MPa}$, respectively, which can fully meet the requirements of SAGD simulation experiments; model internal size is $300 \times 300 \times 200$ $\mathrm{mm}$. There were 54 temperature measurement points in the model, as shown in Figures 9(a) and 9(b). The back of model was also equipped with pistons for compacting the sand layer. The rest of equipment was the same as in the two-dimensional experiment. Figure 10 shows the flow diagram of $3 \mathrm{D}$ experiment.

\subsubsection{Procedures}

(1) Placed the model horizontally and the bottom layer of the model cover according to the requirements of the experimental process and then installed the model simulation well, temperature sensor, heating sheet, and insulation cotton

(2) According to the experimental design, sand, oil, and water were mixed with the mass ratio and then filled into the model to achieve a simulated reservoir thickness of $15 \mathrm{~cm} ; 5 \mathrm{~cm}$ of clay was placed above the model cavity. Considering the interference of air in the filling process and the existence of some voids in the sand, after the filling of oil sand, the mixture of oil and water was continued to be injected proportionally until oil and water occurred at the end of the model

(3) The temperature and pressure of the model were set to $50^{\circ} \mathrm{C}$ and $1 \mathrm{MPa}$. After the model achieved the stable state, steam was injected at the rate of $20 \mathrm{ml} / \mathrm{min}$ (water equivalent). The steam injection temperature was $189^{\circ} \mathrm{C}$. The steam quality was 0.8

(4) In the process of $3 \mathrm{D}$ experiment, the produced oil and water were collected and measured. The 56 temperature transducers recorded the real-time temperature of the model

\section{Results and Discussions}

\subsection{D Visualization Physical Simulations}

3.1.1. Development of Steam Chamber. Based on the temperature field data recorded by thermocouples and the development image captured by digital camera, Figures 11-13 show the images for steam chamber development and the corresponding temperature profiles in three groups of experiment at six points.

(1) Horizontal Distance Was $0 \mathrm{~cm}$. Due to interwell preheating made the temperature between injection and production wells more than $80^{\circ} \mathrm{C}$, the reservoir near the two wells was heated firstly and the viscosity was reduced. With the injection of steam, the viscosity of heavy oil near the injection well was further reduced, and the heavy oil drained into the 

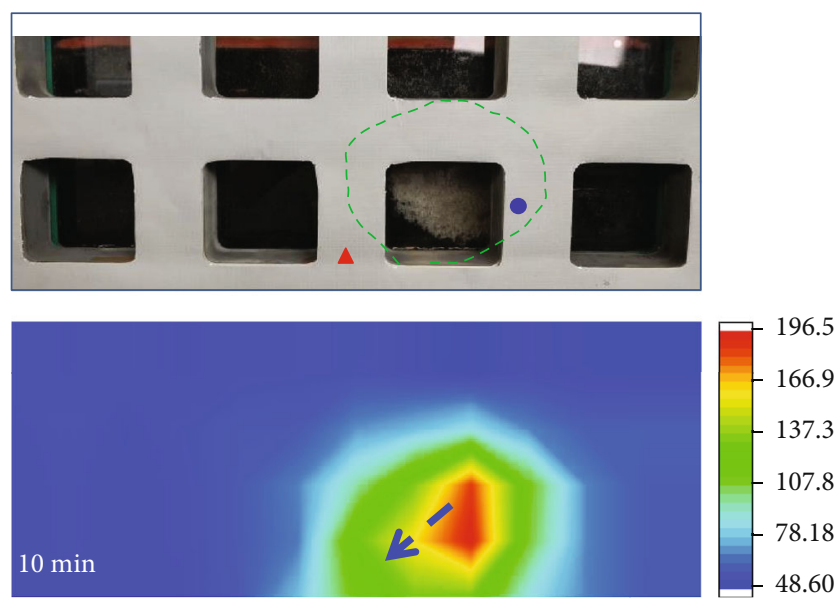

(a)
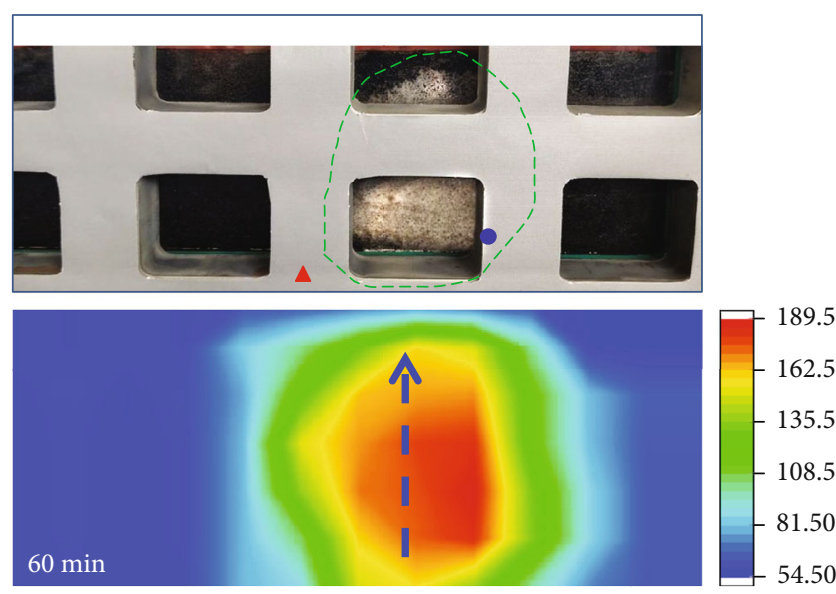

(c)
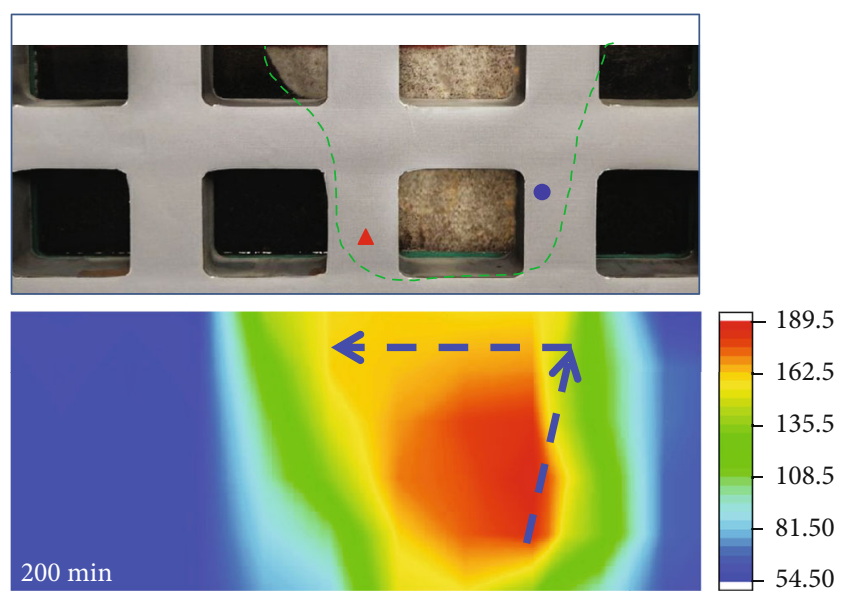

(e)
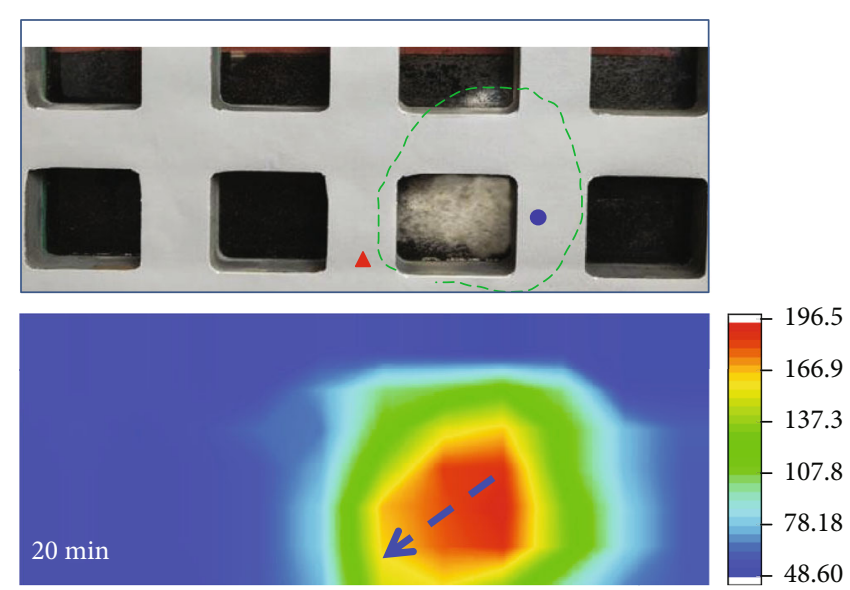

(b)
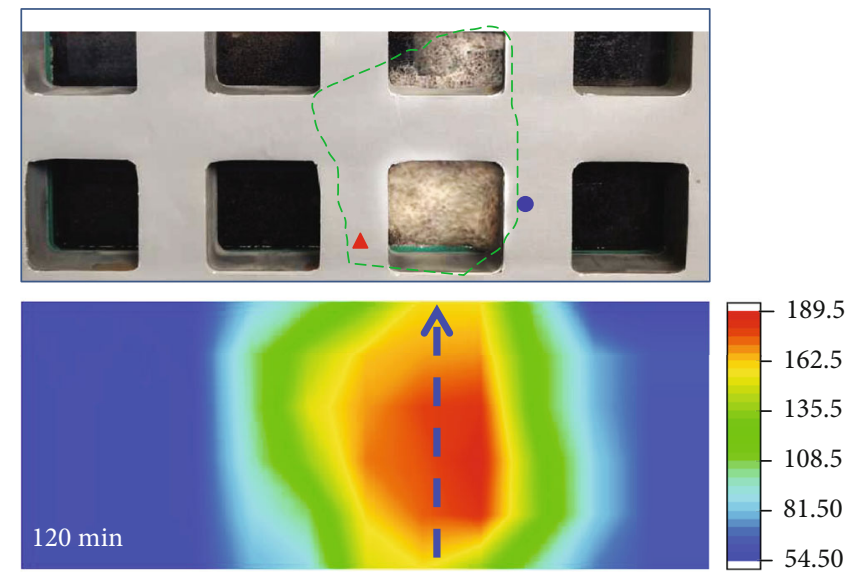

(d)
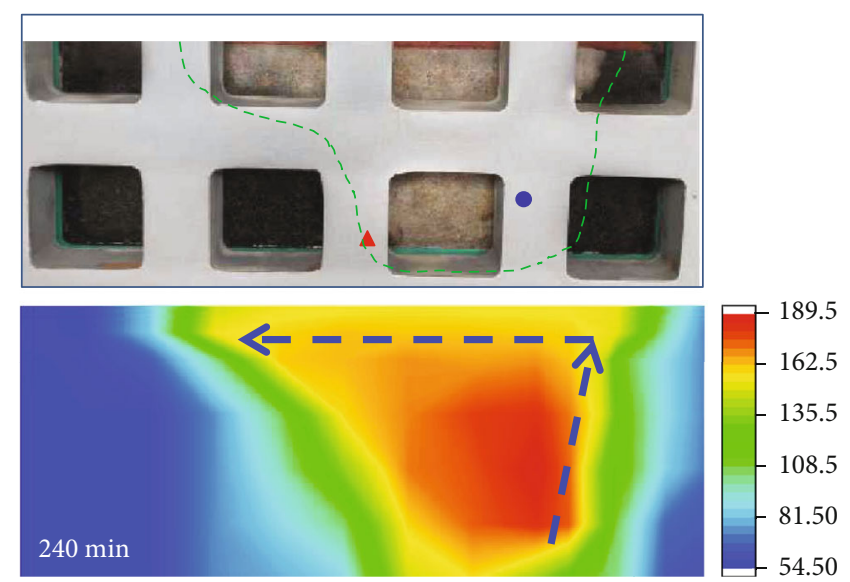

(f)

FIGURE 12: Pictures of steam chamber development and corresponding temperature profiles.

production well under the action of steam driven and gravity [26]. The steam encountered resistance after injecting; thus, the injection pressure increased slightly and the highest temperature reached about $193^{\circ} \mathrm{C}$. Then, subsequent steam occupied the space of heavy oil that had been produced; the steam chamber was initially formed and extended fast toward the producing well, as shown in Figures 11(a) and 11(b). From
$60 \mathrm{~min}$ to $100 \mathrm{~min}$, due to overlap of steam, the steam heated the reservoir above, causing the heavy oil and steam condensate flowed along the liquid-vapor interface [10]. Therefore, the steam chamber began to develop rapidly along the longitudinal direction and reached the top of the model at 100 min, resulting in the shape of steam chamber was slender [42], as shown in Figures 11(c) and 11(d). In addition, it 

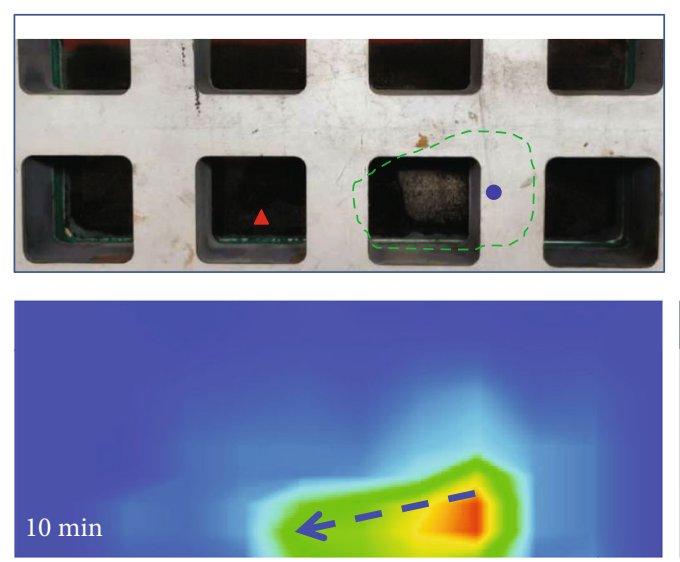

(a)
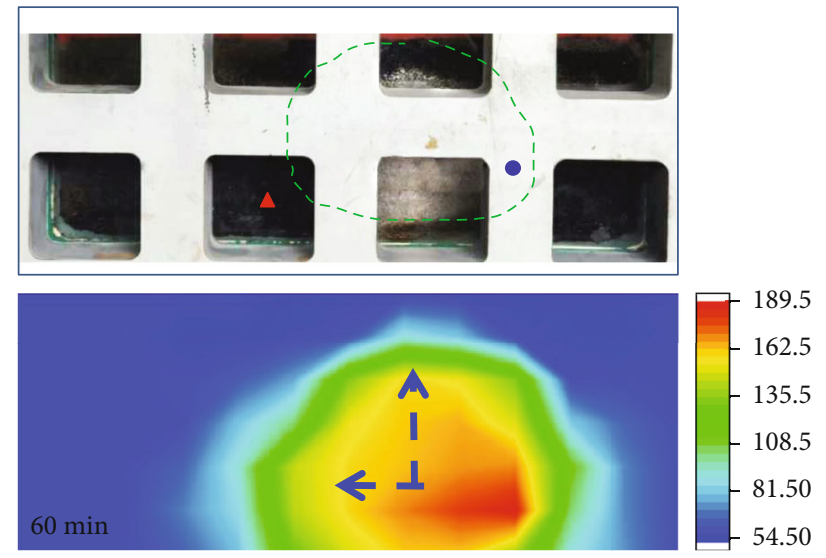

(c)

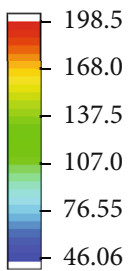

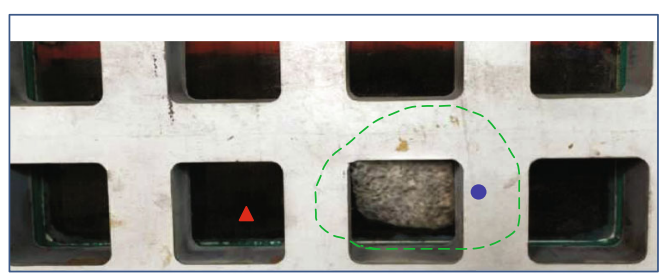
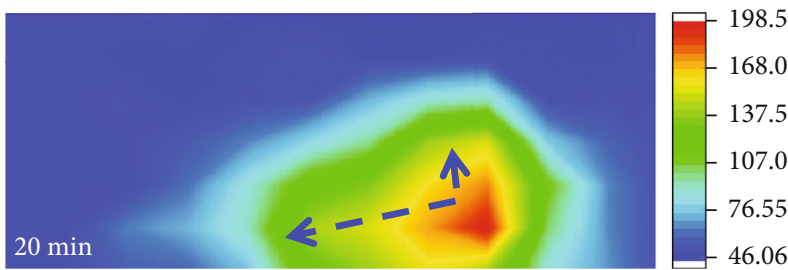

(b)
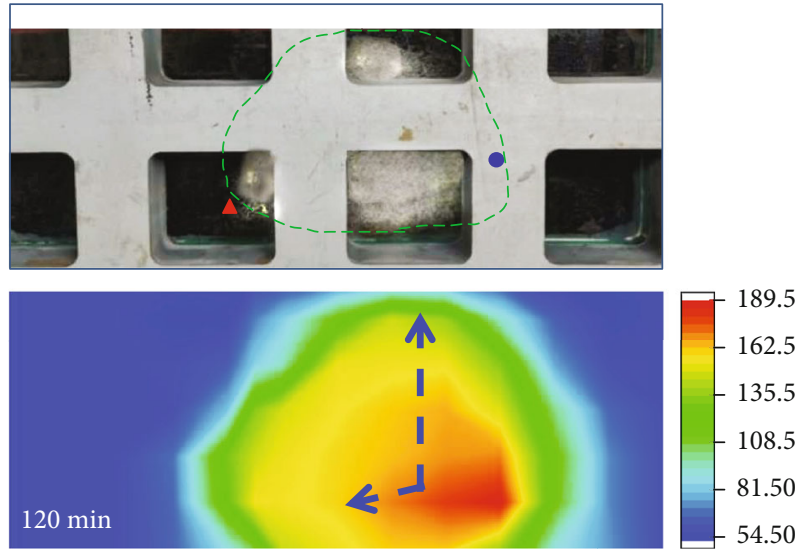

(d)

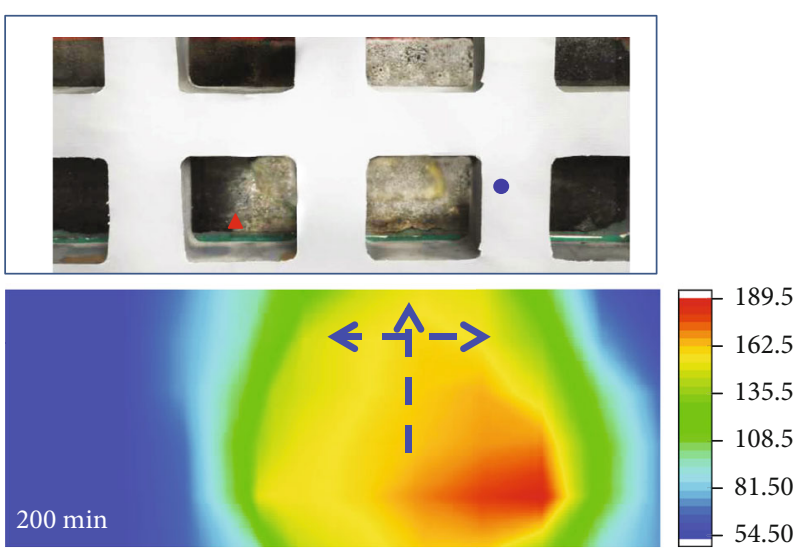

(e)

Figure 13: Continued. 


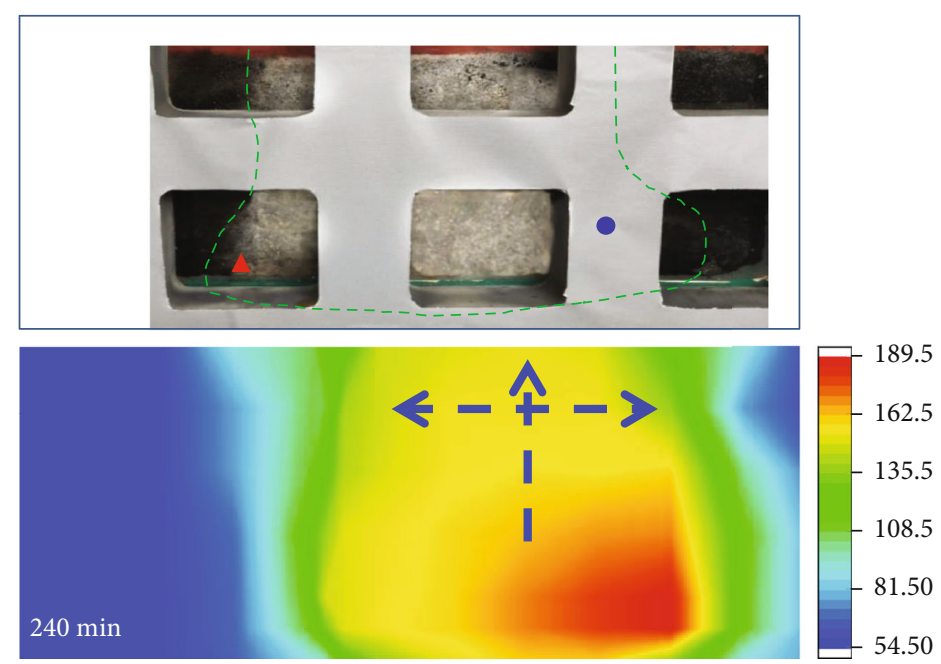

(f)

Figure 13: Pictures of steam chamber development and corresponding temperature profiles.

was found that the production pressure difference was gradually stabilized at about $0.2 \mathrm{MPa}$; the effect of gravity drainage was best at this stage. Thereafter, the steam chamber expanded laterally after $120 \mathrm{~min}$ because the longitudinal sweep of steam was limited by the boundary of model, as shown in Figure 11(e). However, on the one hand, some steam was produced from the producing well because of steam channeling. On the other hand, due to steam lost heat outward when it gathered at top of the model, the steam utilization ratio of heat was decreased obviously and water cut was high, causing that the lateral expansion rate of steam chamber was very slow $[6,26,42]$. Finally, the overall steam chamber was roughly U-shaped at $240 \mathrm{~min}$, as shown in Figure 11(f), and the steam chamber barely developed again.

(2) Horizontal Distance Was $10 \mathrm{~cm}$. Due to the thin thickness of the oil sand reservoir, the steam chamber expanded quickly to the top of the model in the experiment no. 1, which is mainly in longitudinal development. However, it can be seen from the process of experiment no. 2, especially at the early and middle stages, that the lateral sweep range of steam was greater than that of experiment no. 1 obviously.

After steam injection, due to the horizontal distance between injection and production wells had been lengthened, the steam sweep resistance increased as well, which caused that the production pressure was higher than that of experiment no. 1 and the role of steam displacement effect was enhanced, with the highest temperature reached about $196.5^{\circ} \mathrm{C}$. Figure $12(\mathrm{a})$ shows that the steam sweep area extended laterally to the producing well at $10 \mathrm{~min}$, and the lateral development of steam chamber was more obvious because of steam displacement from 10 to $20 \mathrm{~min}$, as shown in Figure 12(b), and it could be seen that the heavy oil between the injection and production wells was basically produced. Meanwhile, the rate of longitudinal development of the steam chamber was decreased under the influence of steam displacement, which causing that more heat was trans- ferred laterally; thus, the steam chamber did not develop to the top until at $120 \mathrm{~min}$, as shown in Figures 12(c) and 12 (d). From $200 \mathrm{~min}$ to $240 \mathrm{~min}$, the steam chamber gradually expanded laterally with the continuous injection of steam; as shown in Figures 12(e) and 12(f), oil production decreased and water cut increased gradually at this time. This indicated a lot of steam heat was transferred outward and heat loss was increased.

(3) Horizontal Distance Was $20 \mathrm{~cm}$. Figures 13(a) and 13(b) show that the highest temperature reached about $198.3^{\circ} \mathrm{C}$ with the further increase of dislocation distance, which indicated that the pressure difference between production and injection was raised. It was obvious that the shape of the steam chamber was flatter than experiment no. 1 and No. 2, which meant the influence of steam displacement increased. However, heat loss was increased during steam displacement, which condensed rapidly into high-temperature water, causing that the strength of the steam overlap was weaken and the expansion rate of the steam chamber was relatively low compared with experiment no. 2, as shown in Figures 13(c) and 13(d). Therefore, the steam chamber reached the top of the model at $200 \mathrm{~min}$, which needed more time than previous experiments and decreased the heat efficiency of steam; the capacity of gravity drainage was also weaken. On the other hand, the lateral expansion of the steam chamber was also limited at the top, as shown in Figures 13(e) and 13(f).

3.1.2. Production Performance Analysis. Figures 14(a)-14(d) provide comparison of oil production rate, injectionproduction pressure difference, water cut, cumulative oilsteam ratio, and oil recovery versus time in three experiments, respectively.

It can be seen from Figure 14(a) that the oil production rate of three experiments all increased rapidly in the early period; this stage corresponded to the rapid formation and expansion of the steam chamber. In addition, Figure 14(b) shows that the injection and production pressure difference gradually 


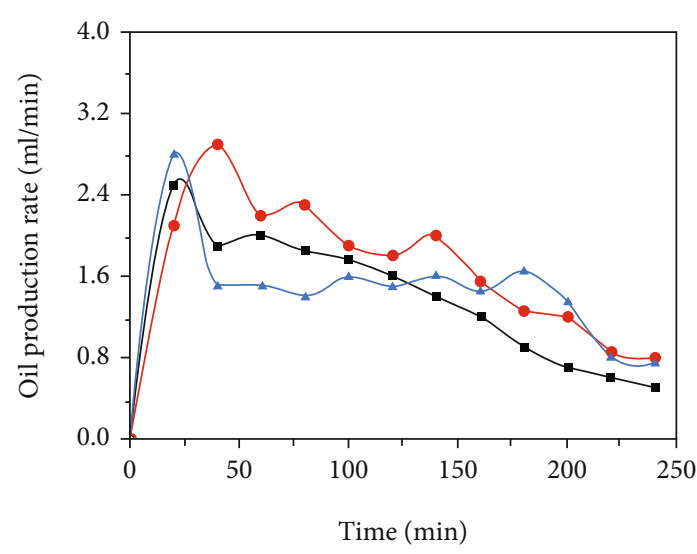

$\rightarrow$ Dislocated distance is $0 \mathrm{~cm}$

- Dislocated distance is $10 \mathrm{~cm}$

$\rightarrow$ Dislocated distance is $20 \mathrm{~cm}$

(a)

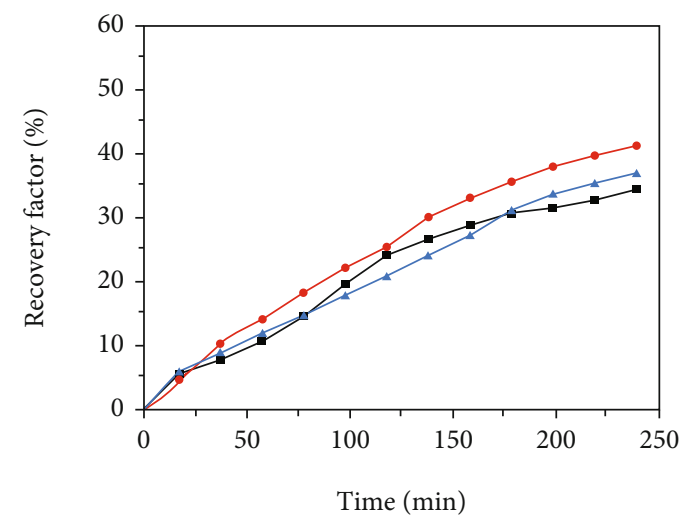

- Dislocated distance is $0 \mathrm{~cm}$

$\rightarrow$ Dislocated distance is $10 \mathrm{~cm}$

$\Longrightarrow$ Dislocated distance is $20 \mathrm{~cm}$

(c)

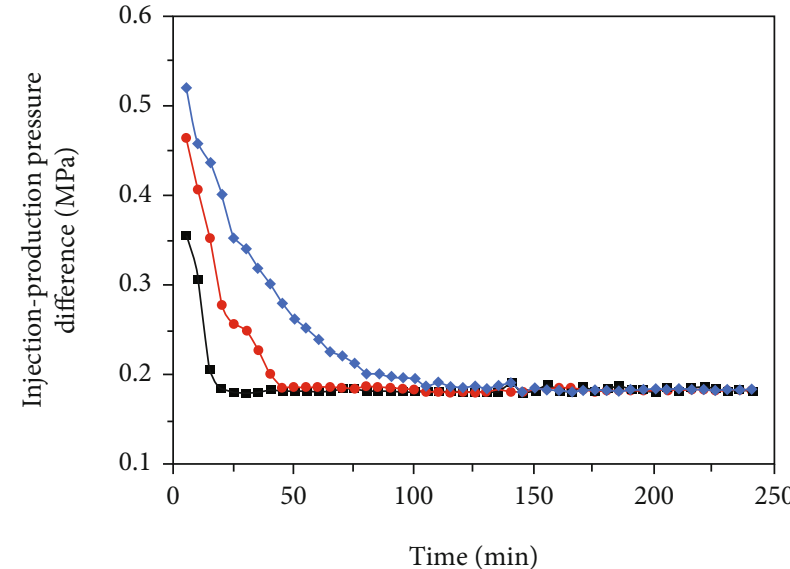

$\rightarrow$ Dislocated distance is $0 \mathrm{~cm}$

- Dislocated distance is $10 \mathrm{~cm}$

- Dislocated distance is $20 \mathrm{~cm}$

(b)

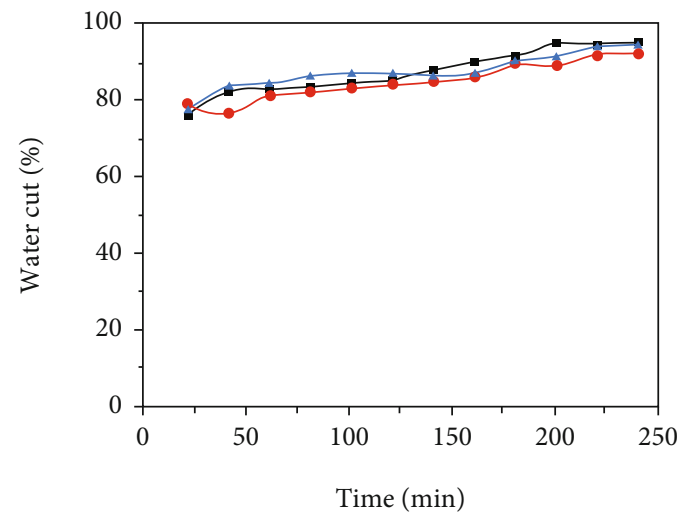

$\rightarrow$ Dislocated distance is $0 \mathrm{~cm}$

$\rightarrow$ Dislocated distance is $10 \mathrm{~cm}$

$\ldots$ Dislocated distance is $20 \mathrm{~cm}$

(d)

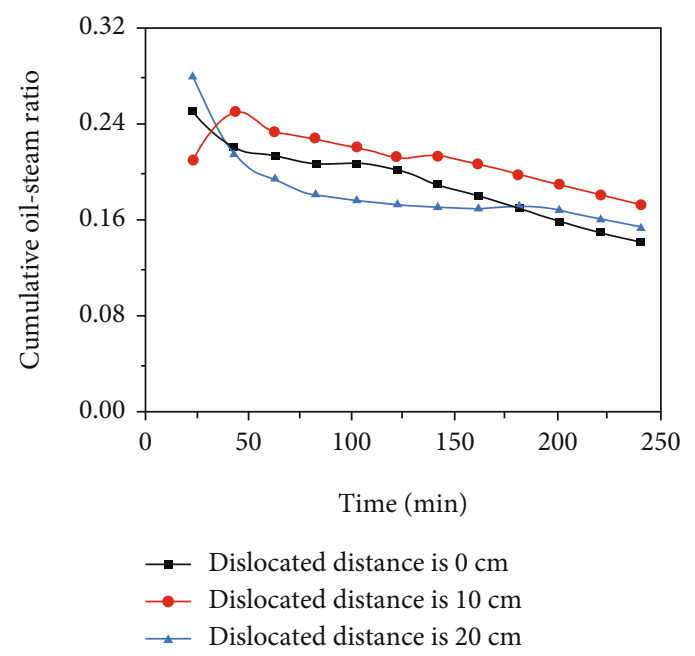

(e)

Figure 14: Comparison of production performance of three experiments. (a) Change of oil production rate with time. (b) Change of injection-production pressure difference with time. (c) Change of recovery factor with time. (d) Change of water cut with time. (e) Change of cumulative oil-steam ratio with time. 

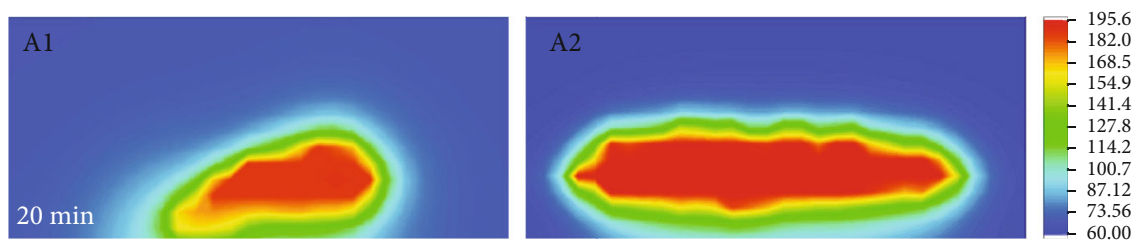

(a) $20 \mathrm{~min}$
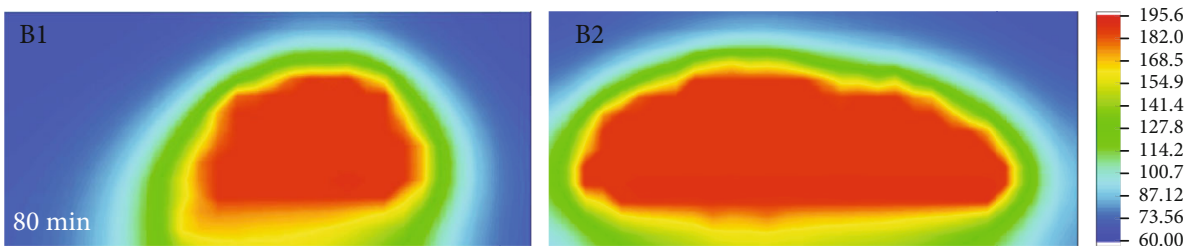

(b) $80 \mathrm{~min}$
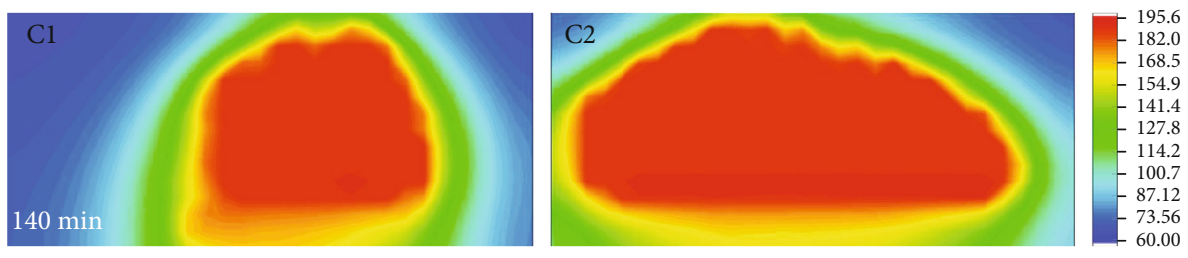

(c) $140 \mathrm{~min}$

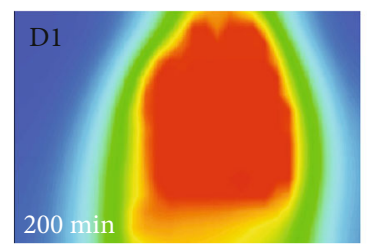

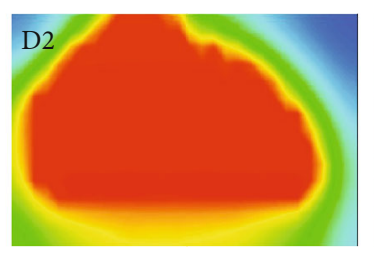

(d) $200 \mathrm{~min}$
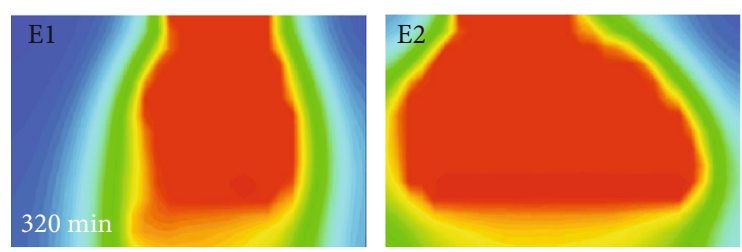

(e) $320 \mathrm{~min}$
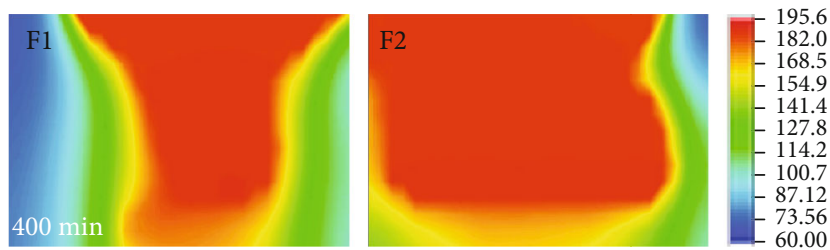

(f) $400 \mathrm{~min}$

Figure 15: (a) Temperature distribution at $20 \mathrm{~min}$ : (A1) perpendicular to wells; (A2) along wells. (b) Temperature distribution at 80 min: (B1) perpendicular to wells; (B2) along wells. (c) Temperature distribution at $140 \mathrm{~min}$ : (C1) perpendicular to wells; (C2) along wells. (d) Temperature distribution at $200 \mathrm{~min}$ : (D1) perpendicular to wells; (D2) along wells. (e) Temperature distribution at 320 min: (E1) perpendicular to wells; (E2) along wells. (f) Temperature distribution at $400 \mathrm{~min}$ : (F1) perpendicular to wells; (F2) along wells. Profiles of temperature distribution in 3D physical dislocated well SAGD experiment.

dropped from the beginning of the maximum value to a stable value, which indicated that the SAGD production relies on a combination of steam flooding and gravity drainage. From about $50 \mathrm{~min}$ to $160 \mathrm{~min}$, the overall oil production rate all had tendency to stability and water cut increased slowly, with a stable injection and production pressure difference; this stage corresponded to the longitudinal development of the steam chamber, which indicated that oil production mainly relied on stable gravity drainage. Then, three groups of SAGD production gradually went into exhaustion, with a continuous decline of oil production rate and rising of water cut; as shown in Figure 14(d), this stage corresponded to the slow lateral development of the steam chamber at the top of model.
Compared with the comparison of production performance of three experiments, it can be concluded that the production performance was best when the transverse dislocation distance was $10 \mathrm{~cm}$, with the $41.6 \%$ oil recovery, which was $7.6 \%$ and $2.3 \%$ higher than that of $0 \mathrm{~cm}$ and $20 \mathrm{~cm}$, respectively, as shown in Figure 14(c). Furthermore, the cumulative oil-steam ratio was also higher than that of the other two groups with time, as shown in Figure 14(e). Benefiting from the dislocation, the combined effect of flooding and drainage of the dislocated well SAGD was strengthened, especially in experiment no. 2. However, when the dislocation distance is too large, such as experiment no. 3, steam mainly migrated between injection and 


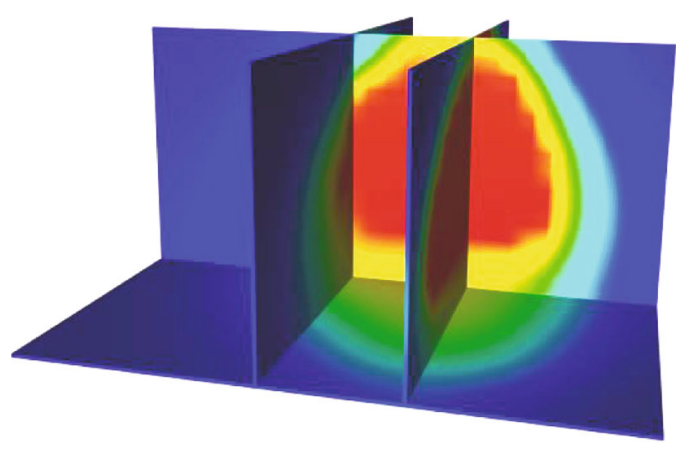

(a)

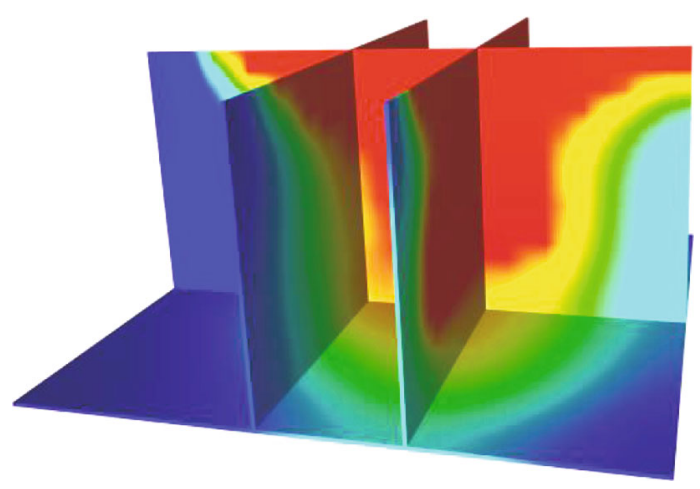

(b)

Figure 16: A three-dimensional diagram of the temperature field in 3D physical experiment. (a) Middle stage. (b) End stage.

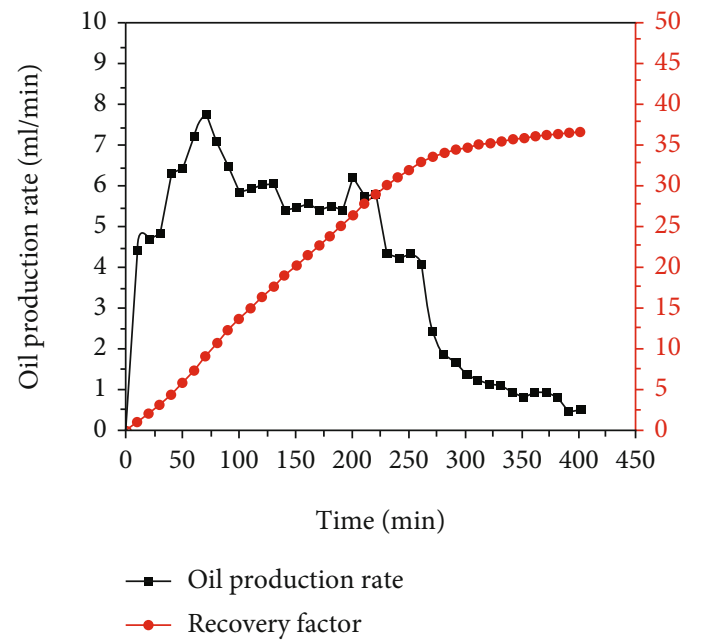

(a)

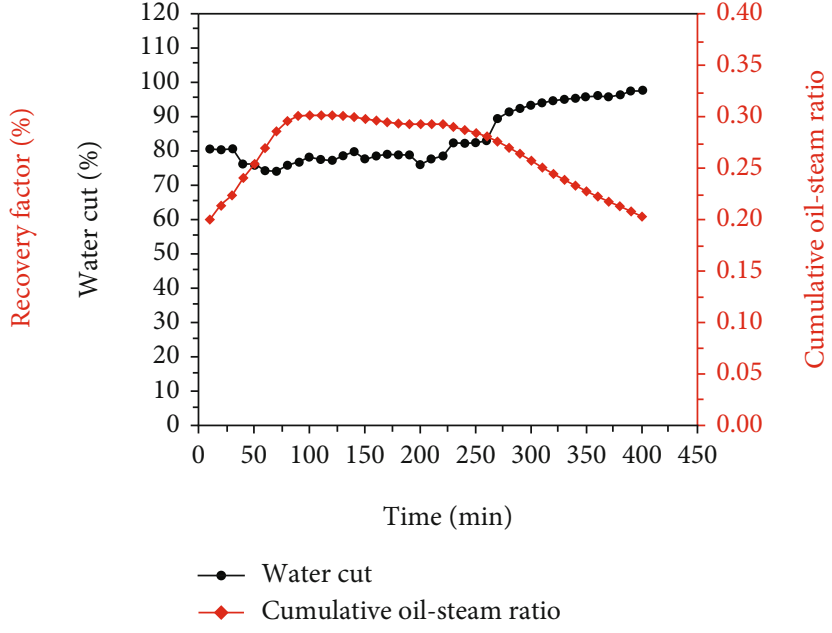

(b)

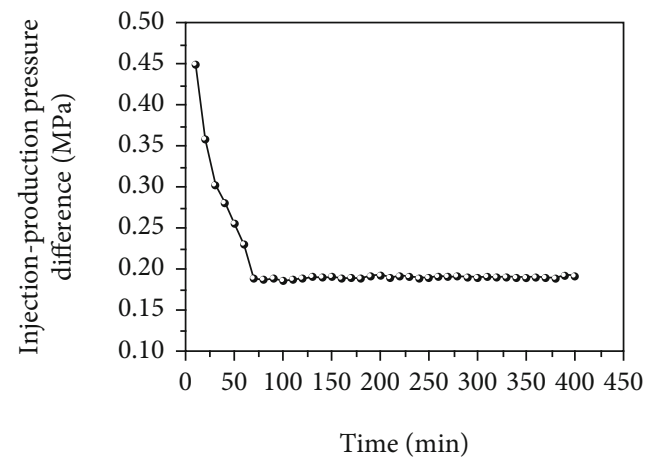

(c)

FIGURE 17: Production performance of 3D dislocated well SAGD experiment. (a) Change of oil production rate with time and recovery factor with time. (b) Change of water cut with time and cumulative oil-steam ratio with time. (c) Change of injection-production pressure difference with time.

production wells to loss heat; the development of the steam chamber was impeded as a result. Therefore, it is not difficult to find that appropriate dislocation distance not only can make the combination effect of steam displacement and gravity drainage better but also can increase the sweep efficiency of steam and promote the transverse development of steam chamber more effectively to enhance oil recovery.
3.1.3. 3D Physical Simulation. Based on the visualization physical simulation of $10 \mathrm{~cm}$ transverse distance, a 3D physical experiment was carried out to deeply study the production mechanism of SAGD after changing horizontal distance between two wells.

3.1.4. Development of Steam Chamber. Figures 15(a)-15(f) show the images for the temperature distribution of this 
SAGD process along with well and perpendicular to well at different times. Figures 15(a) and 15(b) show the threedimensional diagram of the temperature field in middle and end production stage.

From the temperature field distribution of each time above, as shown in Figures 15 and 16, it can be found that the shape of steam swept zone in this experiment matched well with the observed steam chamber in $2 \mathrm{D}$ visualization experiment. We can see that steam chamber tended to grow laterally to the producing well first because of intensive steam displacement, then it started to develop longitudinally, so the shape of the steam chamber was wide below and narrow above. In the middle stage, the steam chamber mainly developed longitudinally because of steam overlap, with the exploitation of heavy oil; the steam chamber and steamswept area expanded gradually. As the steam sweep area reached the top of the model, the longitudinal development of the steam chamber was restricted by the model boundary, and the steam chamber began to expand toward both sides to heat the heavy oil. However, due to the large amount of steam heat loss toward outside in the end production stage, the rate of lateral expansion was very slow, which led to arrested development of steam chamber.

3.1.5. Production Performance Analysis. Figures $17(a)-17(\mathrm{c})$ provide production performance of two stages, including oil production rate, recovery factor, pressure difference between production and injection, water cut, and cumulative oilsteam ratio, respectively.

In the first $80 \mathrm{~min}$, due to existence of injectionproduction pressure difference in the early process, as shown in Figure 17(c), the steam priority heated and displaced the heavy oil between two wells; meanwhile, steam also heated the heavy oil on the top to form steam chamber, as shown in Figure 17(a). Therefore, benefited from the combination of steam displacement and gravity drainage, the overall oil production rate remained at a high level, the cumulative oil production increased rapidly, cumulative oil-steam ratio also increased, and water cut decreased gradually, as shown in Figures 17(a) and 17(d). From $80 \mathrm{~min}$ to $200 \mathrm{~min}$, most steam started to propagate mainly upward because of gravity override; then, the steam chamber developed mainly longitudinally. In addition, the injection-production pressure difference began to be stabilized, which indicated that this stage mainly relied on gravity drainage; thus, the oil production rate was stable overall and the water cut gradually increased. After $200 \mathrm{~min}$, the oil production declined rapidly, water cut gradually increased to above $90 \%$, and the cumulative oil-steam ratio declined continually, indicating that the steam chamber development basically stagnated. Finally, the steam chamber no longer expanded obviously and the water cut exceeded $95 \%$.

\section{Summary and Conclusions}

To solve the problem of limiting expansion area of steam chamber caused by thin reservoir thickness in process of SAGD production, based on the $2 \mathrm{D}$ visualization and $3 \mathrm{D}$ physical experiments to study the production mechanism of
SAGD after changing horizontal distance between two wells, the following conclusions can be drawn:

(1) In $2 \mathrm{D}$ visualization experiment, the steam chamber development shape of SAGD with the generation of horizontal well spacing between two wells was distinct from traditional SAGD; the lateral development of steam chamber was effectively promoted because of better dual effects of steam displacement and gravity drainage, improving the transverse sweep efficiency of steam

(2) Production performance shows that the final recovery of two groups of SAGD with $10 \mathrm{~cm}$ and $20 \mathrm{~cm}$ horizontal well spacing improves the oil recovery by about $7.6 \%$ and $2.3 \%$ than that of the traditional SAGD group with $0 \mathrm{~cm}$ horizontal well spacing, indicating that the generation of appropriate horizontal distance can promote steam chamber development, restrain the rapid increase of water cut, stable cumulative oil-steam ratio, and enhance oil recovery; nevertheless, the overlarge horizontal well spacing can also hinder the development of the steam chamber, resulting in the decrease of recovery factor

(3) Compared with the results of $2 \mathrm{D}$ and $3 \mathrm{D}$ physical experiments, we find that the development process and shape of steam chamber is basically the same. The production process also can be divided into three stages: combination of displacement and drainage stage, stable drainage stage, and exhaustion stage

\section{Nomenclature}

$\pi_{1}$ : Ratio of steam injection volume to movable oil volume

$i_{s}: \quad$ Steam injection intensity $(\mathrm{t} / \mathrm{d})$

$\Delta S$ : Oil saturation

$t$ : Production time (s)

$\varnothing$ : Porosity

$L$ : Length of horizontal well (m)

$\pi_{2}$ : Ratio of gravity and viscosity force

$K: \quad$ Permeability $\left(10^{-3} \mu \mathrm{m}^{2}\right)$

$\rho_{o}:$ Oil density $\left(\mathrm{kg} / \mathrm{m}^{3}\right)$

$\mu_{o}$ : Oil viscosity (mPa $\left.\cdot \mathrm{s}\right)$

$t_{D}$ : Degree of exploitation

g: Acceleration of gravity $\left(\mathrm{m} / \mathrm{s}^{2}\right)$

$\alpha$ : Thermal diffusivity $\left(\mathrm{m}^{2} / \mathrm{s}\right)$

$n$ : Viscosity temperature characteristic parameter of crude oil

$v_{s}:$ Kinematic viscosity of steam $\left(\mathrm{m}^{2} / \mathrm{s}\right)$

$h$ : Thickness of reservoir $(\mathrm{m})$

$F_{o}$ : Relative ratio of heat transfer rate and heat storage rate

$N_{s}$ : Relative ratio of power and loss

$b$ : Horizontal well spacing $(\mathrm{m})$

$\Delta p$ : Bottom hole flow pressure difference between the injection and producing well (MPa)

$Q_{h}$ : Horizontal well production $\left(\mathrm{m}^{3} / \mathrm{d}\right)$. 


\section{Data Availability}

The [DATA TYPE] data used to support the findings of this study are included within the article.

\section{Conflicts of Interest}

The authors declare that they have no conflicts of interest.

\section{Acknowledgments}

The research was supported by the Jiangsu IndustryUniversity Research Project for the study on cold recovery and stimulation technology of nonhydrocarbon gas $\left(\mathrm{N}_{2} / \mathrm{CO}_{2}\right)$ heavy oil with multieffect chemical agent (No. BY2019068) and the Postgraduate Research \& Practice Program of Jiangsu Province for the study on the camellia saponin extraction and $\mathrm{CO}_{2}$ saponin foam with high salinity (No. KYCX20_2577).

\section{References}

[1] T. Babadagli, “Technology focus heavy oil," Journal of Petroleum Technology, vol. 71, no. 4, pp. 68-68, 2019.

[2] W E Council, Oil Sands and Heavy Oil, Encyclopedia of Energy, 2004.

[3] A. Mukhametshina and E. Martynova, "Electromagnetic heating of heavy oil and bitumen: a review of experimental studies and field applications," Journal of Petroleum Engineering, vol. 2013, Article ID 476519, 7 pages, 2013.

[4] S. R. Larter and I. M. Head Erratum, "Oil sands and heavy oil: origin and exploitation," Elements, vol. 10, no. 4, pp. 277-283, 2014.

[5] M. Fustic, S. M. Hubbard, R. Spencer et al., "Recognition of down-valley translation in tidally influenced meandering fluvial deposits, Athabasca Oil Sands (Cretaceous), Alberta, Canada," Marine and Petroleum Geology, vol. 29, no. 1, pp. 219232, 2012.

[6] S. R. Larter, J. Adams, I. D. Gates, B. Bennett, and H. Huang, "The origin, prediction and impact of oil viscosity heterogeneity on the production characteristics of tar sand and heavy oil reservoirs," Journal of Canadian Petroleum Technology, vol. 47 , no. $1,2008$.

[7] E. Vittoratos and A. R. Kovscek, "Doctrines and realities in viscous and heavy-oil reservoir engineering," Journal of Petroleum Science and Engineering, vol. 178, pp. 1164-1177, 2019.

[8] X. Dong, H. Liu, Z. Chen, K. Wu, N. Lu, and Q. Zhang, "Enhanced oil recovery techniques for heavy oil and oilsands reservoirs after steam injection," Applied Energy, vol. 239, pp. 1190-1211, 2019.

[9] F. Chen, H. Liu, X. Dong et al., "A new analytical model to predict oil production for cyclic steam stimulation of horizontal wells," in SPE Western Regional Meeting, San Jose, CA, USA, April 2010.

[10] S. Huang, X. Chen, H. Liu et al., "Experimental and numerical study of steam-chamber evolution during solvent- enhanced steam flooding in thin heavy-oil reservoirs," Journal of Petroleum Science and Engineering, vol. 172, pp. 776-786, 2019.

[11] R. M. Butler, "A new approach to the modelling of steamassisted gravity drainage," Journal of Canada Petroleum Technology, vol. 24, no. 3, pp. 42-51, 1985.
[12] R. M. Butler, "Steam-assisted gravity drainage: concept, development, performance and future," Journal of Canadian Petroleum Technology, vol. 33, no. 2, pp. 44-50, 1994.

[13] I. D. Gates and N. Chakrabarty, "Optimization of steam assisted gravity drainage in Mcmurray reservoir," Journal of Canadian Petroleum Technology, vol. 45, no. 9, pp. 54-62, 2006.

[14] A. H. Syed, N. Mosavat, J. Riordon et al., "A combined method for pore-scale optical and thermal characterization of SAGD," Journal of Petroleum Science and Engineering, vol. 146, pp. 866-873, 2016.

[15] F. Argüelles-Vivas and T. Babadagli, "Pore-scale investigations on the dynamics of gravity-driven steam-displacement process for heavy-oil recovery and development of residual oil saturation: a 2D visual analysis," SPE Journal, vol. 21, no. 6, pp. 1943-1959, 2016.

[16] D. Baghernezhad and M. Siavashi, "Optimal scenario design of steam-assisted gravity drainage to enhance oil recovery with temperature and rate control," Energy, vol. 166, pp. 610-623, 2019.

[17] X. Jia, T. Qu, H. Chen, and Z. Chen, "Transient convective heat transfer in a steam-assisted gravity drainage (SAGD) process," Fuel, vol. 247, pp. 315-323, 2019.

[18] S. Huang, L. Yang, Y. Xia, M. du, and Y. Yang, “An experimental and numerical study of a steam chamber and production characteristics of SAGD considering multiple barrier layers," Journal of Petroleum Science and Engineering, vol. 180, pp. 716-726, 2019.

[19] D. Ji, H. Zhong, M. Dong, and Z. Chen, "Study of heat transfer by thermal expansion of connate water ahead of a steam chamber edge in the steam-assisted-gravity-drainage process," Fuel, vol. 150, pp. 592-601, 2015.

[20] A. M. Al-Bahlani and T. Babadagli, "SAGD laboratory experimental and numerical simulation studies: a review of current status and future issues," Journal of Petroleum Science and Engineering, vol. 68, no. 3-4, pp. 135-150, 2009.

[21] X. Chen, R. S. Nie, Y. L. Jia, and L. X. Sang, “The application of Stefan problem in calculating the lateral movement of steam chamber in SAGD," Mathematical Problems in Engineering, vol. 2015, Article ID 372581, 11 pages, 2015.

[22] K. Sasaki, S. Akibayashi, H. Kosukegawa, M. Kato, and K. Ono, "Experimental study on initial stage of SAGD process using 2dimensional scaled model for heavy oil recovery," in International Conference on Horizontal Well Technology, Calgary, Alberta, Canada, November 1996.

[23] H. Liu, L. Cheng, S. Huang, P. Jia, and M. Chen, "Evolution characteristics of SAGD steam chamber and its impacts on heavy oil production and heat consumption," International Journal of Heat and Mass Transfer, vol. 121, pp. 579-596, 2018.

[24] Z. Wang, Z. Li, H. K. Sarma et al., "A visualization experimental study on gas penetration through interlayer to improve SAGD performance," Journal of Petroleum Science and Engineering, vol. 177, pp. 959-970, 2019.

[25] J. Li, L. Zhang, F. Yang, and L. Sun, "Positive measure and potential implication for heavy oil recovery of dip reservoir using SAGD based on numerical analysis," Energy, vol. 193, article 116582, 2020.

[26] H. Chen, Z. Wang, K. Wang, Z. Li, and S. Li, "Investigation of EOR mechanism for flue gas assisted SAGD," Journal of Petroleum Science and Engineering, vol. 193, article 107420, 2020. 
[27] K. H. Chung, "A theoretical and experimental study of steam assisted gravity drainage process," in Proc. 4th UNITAR/UNDP Int. Conf. on Heavy Crude and Tar Sands, vol. 4, pp. 191-210, 1989.

[28] M. Nukhaev, V. Pimenov, A. Shandrygin, and V. V. Tertychnyi, "A new analytical model for the SAGD production phase," in SPE Annual Technical Conference and Exhibition, San Antonio, TX, USA, September 2006.

[29] M. Siavashi, H. Garusi, and S. Derakhshan, "Numerical simulation and optimization of steam-assisted gravity drainage with temperature, rate, and well distance control using an efficient hybrid optimization technique," Numerical Heat Transfer, Part A: Applications, vol. 72, no. 9, pp. 721-744, 2017.

[30] X. Dong, H. Liu, Z. Chen, and P. Qi, “An empirical correlation to predict the SAGD recovery performance," Journal of Computational Methods in Sciences and Engineering, vol. 17, no. 3, pp. 333-345, 2017.

[31] Q. Zhang, H. Liu, X. Dong, Y. Liu, G. Li, and Y. Wang, "A new comprehensive model to estimate the steam chamber expansion and recovery performance of entire SAGD process," Journal of Petroleum Science and Engineering, vol. 185, p. 106629, 2020.

[32] R. Munoz, "Simulation sensitivity study and design parameters optimization of SAGD process," in SPE Heavy Oil ConferenceCanada, Calgary, Alberta, Canada, June 2013.

[33] K. Dou and A. Li, "The influence of interlayer on the expansion of steam chamber of oil sand SAGD development," IOP Conference Series: Earth and Environmental Science, vol. 631, no. 1, article 012076, 2021.

[34] N. You, S. Yoon, and C. W. Lee, "Steam chamber evolution during SAGD and ES-SAGD in thin layer oil sand reservoirs using a 2-D scaled model," Journal of Industrial and Engineering Chemistry, vol. 18, no. 6, pp. 2051-2058, 2012.

[35] O. Mohammadzadeh, N. Rezaei, and I Chatzis, "Pore-scale performance evaluation and mechanistic studies of the solventaided SAGD (SA-SAGD) process using visualization experiments," Transport in Porous Media, vol. 108, pp. 437-480, 2015.

[36] S. R. Bagheri, "Experimental and simulation study of the steam-foam process," Energy \& Fuels, vol. 31, no. 1, pp. 299310, 2017.

[37] R. Li, S. R. Etminan, and Z. Chen, "Chemical additives and foam to enhance SAGD performance," in SPE Canada Heavy Oil Technical Conference, Calgary, Alberta, Canada, June 2015.

[38] H. Shijun, X. Hao, W. Shaolei, H. Chenghui, and Y. Yang, "Physical simulation of the interlayer effect on SAGD production in Mackay river oil sands," Fuel, vol. 183, no. 1, pp. 373-385, 2016.

[39] K. D. Kimber, S. M. F. Ali, and V. R. Puttagunta, "New scaling criteria and their relative merits for steam recovery experiments," Journal of Canadian Petroleum Technology, vol. 27, no. $4,1988$.

[40] Q. Doan, S. M. F. Ali, and A. E. George, "Scaling criteria and model experiments for horizontal wells," Journal of Canadian Petroleum Technology, vol. 31, no. 9, pp. 57-65, 1992.

[41] Y. Wu, X. Liu, X. du et al., "Scaled physical experiments on drainage mechanisms of solvent-expanded SAGD in superheavy oil reservoirs," Petroleum Exploration and Development, vol. 47, no. 4, pp. 820-826, 2020.

[42] S. Li, T. Yu, Z. Li, and K. Zhang, "Experimental investigation of nitrogen-assisted SAGD in heavy-oil reservoirs: a twodimensional visual analysis," Fuel, vol. 257, article 116013, pp. 1-16, 2019. 